\title{
2003 MRS Fall Meeting Presents Advancements and Emerging Fields in Materials Research
}

The 2003 Materials Research Society Fall Meeting brought together an array of revelations in which materials design is built upon nature's design, from synthesized diamond and facilitation of the growth of vital organs to the combination of organic and inorganic components in nanotechnology. Held December 1-5 at the Hynes Convention Center and Sheraton Boston Hotel and Towers in Boston, Mass., the Meeting captured areas of continuing growth as well as emerging fields in materials research. Meeting chairs Paula T. Hammond (Massachusetts Institute of Technology), Rommel Noufi (National Renewable Energy Laboratory), Fred Roozeboom (Philips Research), and Susan Trolier-McKinstry (The Pennsylvania State University) divided the 38 technical symposia into eight clusters: Integrated Device Technology; Organic, Soft, and Biological Materials; Nano- to Microstructured Materials; Inorganic Materials and Films; Photonics; Energy Storage, Generation, and Transport; Information Storage Materials; and Design of Materials by Man and Nature. The Meeting included six days of scientific and technical talks, poster sessions, the awards ceremony, a plenary session, tutorials, special events, an exhibit, and other activities, with more than 4200 papers presented in oral and poster sessions to over 4800 attendees.

\section{Technical Talks}

Typically, nature is mimicked in materials research in order to inform technology; in the field of gems, the design is copied in the manufacture of diamonds for jewelry. In Symposium II, rival technologies were presented on the synthesis of diamonds by the use of high-pressure high-temperature (HPHT) annealing-particularly using split-sphere technology (R. Abbaschian of the Univ. of Florida) - and by chemical vapor deposition (B. Deljanin of the European Gemological Laboratory in Vancouver and EGLUSA in New York).

The scientists argued that their techniques offer an economically viable way to synthesize large diamonds. Since HPHT annealing can be used to change the color of undesirable diamonds, M.S. Hall of the Gemological Institute of America discussed ways to distinguish diamonds that have been HPHT-annealed from untreated diamonds. Different techniques are used to obtain different colors. The introduction of B impurities will impart a blue color, and $\mathrm{N}$ a yellow color. However, other colors are produced by impurities coupled with irradiation and/or heat or pressure treatments. Deljanin has fabricated diamonds in a range of colors, including pink. This is significant because intensely colored diamonds are extremely rare in nature.

Alternatively, technology utilized in materials research is used to identify the source of mined gems. At the Basel Fair in Switzerland two years ago, a highquality emerald was identified by its owners as originating in Colombia. Later, it was revealed that it had actually come from a mine in Afghanistan. A. Cheilletz and P. de Donato (CNRS) described the use of infrared microscopy in determining the geological origins of emeralds from around the world. They showed that water with one deuterium atom substituted for one hydrogen atom (HOD), which is trapped in the channels of an emerald crystal along with normal water, has a characteristic infrared spectrum that can be linked to each of the major emerald mines. Positive identification of the origin is thus now possible. The researchers patented their analytical process.

Materials research is also capitalizing on the study of nature's design in the fabrication of vital organs for transplants.

"Tissue engineering is in the Wright Brothers era at present rather than in the stealth aircraft era," said J. Vacanti (Harvard Medical School), regarding his clinical perspective on the problems and potential for tissue-engineering a whole vital organ.

In Symposium F, Vacanti, a pediatric surgeon who performs transplantation of organs in children, showed examples of several patients who received transplant organs and subsequently grew up healthy. Vacanti reported that the number of people waiting for a vital organ in the United

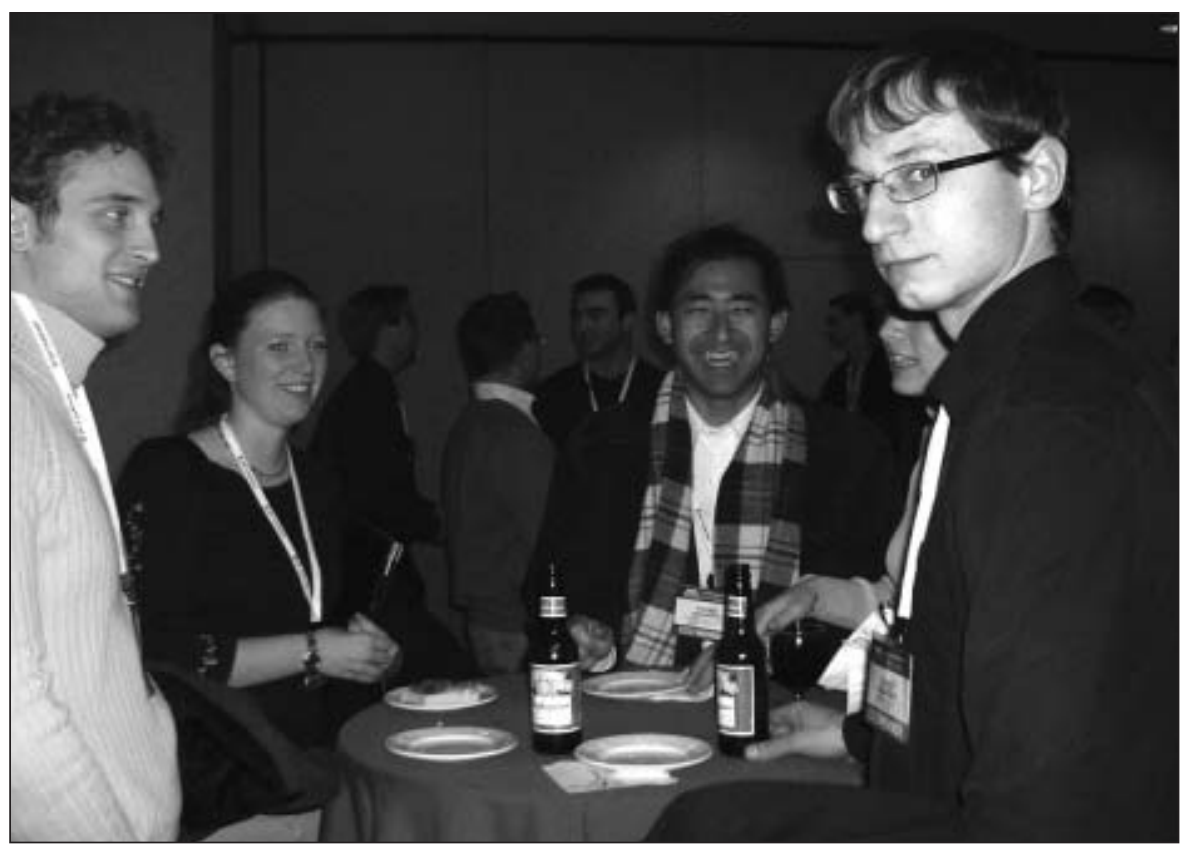

Students had an opportunity to mingle and network in a relaxed atmosphere at the Student Mixer. More than 200 people attended the popular event. 
States has risen from 25,000 in 1992 to over 80,000 today. The growth of vital organs by means of tissue engineering would alleviate the shortage of organs.

Every design in tissue engineering requires matching surface area to volume for effective mass transfer to deliver oxygen and nutrients. Vacanti presented the example of a current project-the Center for the Integration of Medicine and Innovative Technology-wherein a research group is attempting to use stem cells to grow a liver. MEMS technology is being used to create vascular circuitry on a scaffold layer. The layer is then stacked to yield the $z$ axis of a tissue. This approach has been effective for the flow of red blood cells through the system and also has been shown to maintain the life of cells in a test.

Materials science also tackles another shortage in the medical world, that of viable grafting materials-especially autografts for the more than one million bone grafts performed worldwide every year. In Symposium F, S.A. Doherty of Cambridge Scientific, Inc. introduced his company's bone-graft substitute called DONTEX, a synthetic material made of poly(propylene glycol-co-fumaric acid) and unsaturated polyester. The polyester, combined with hydroxyapatite and an effervescent agent, undergoes a crosslinking reaction and expands to fill the void in the bone structure. The effervescent agent causes the formation of an interconnected pore structure consisting of pores ranging from $50 \mu \mathrm{m}$ to $500 \mu \mathrm{m}$ in diameter. Native bone infiltrates the pores prior to the biodegradation of the polymer. The system was tested in a mandibular defect in a laboratory rat-a non-load-bearing, nonsterile environment. Autografted bone performed the best, as expected, but DONTEX and DONTEX plus autograft cells satisfactori- ly repaired the void in the mandibular bone. The initial primary target for the product is periodontal applications.

In an overview of structural DNA nanotechnology from a materials viewpoint, N.C. Seeman (New York Univ.), in Symposium $\mathrm{H}$, said that the central concept of this field is to combine DNA to form structural lattices. Primary objectives include architectural control, nanotechnological device development, and selfreplicating systems. DNA molecules are of interest because they have several advantageous characteristics, including predictable intermolecular interactions and accessibility by well-established, automated chemistry. DNA motifs have been used to form a cube, a truncated octahedron, several deliberately designed knots, and Borromean rings (three interlinked circles). Algorithmic constructions corresponding to XOR operations have also been performed. Challenges ahead,

\section{ACRONYM KEY}

2D: two-dimensional

3D: three-dimensional

ACS: American Chemical Society

AFM: atomic force microscopy

AFOSR: Air Force Office of Scientific Research

AFRL: Air Force Research Laboratory

AIST: National Institute of Advanced

Industrial Science and Technology

ANL: Argonne National Laboratory

ARO: Army Research Office

BES: Basic Energy Sciences

BST: barium strontium titanate

CC: coated conductor

CIMIT: Center for the Integration of Medicine and Innovative Technology

CMOS: complementary metal oxide semiconductor

CNRS: Centre National de la Recherche Scientifique

CRI: color rendering index

CVD: chemical vapor deposition

DARPA: Defense Advanced Research Projects Agency

DHS: U.S. Department of Homeland Security

DLTS: deep-level transient spectroscopy

DMR: Division of Materials Research

DOE: U.S. Department of Energy

DPN: dip-pen nanolithography

DVD: digital versatile disk

EAP: electroactive polymers

ECD: Energy Conversion Devices, Inc.

EGL: European Gemological Laboratory

EPFL: Ecole Polytechnique Fédérale de Lausanne

FET: field-effect transistor

FRAM: ferroelectric random-access memory

FY: fiscal year

GE: General Electric

GM: General Motors
GUIRR: Government-University-Industry Research Roundtable

HDL: high-density liquid

HPHT: high-pressure high-temperature

HSARPA: Homeland Security Advanced

Research Projects Agency

HTS: high-temperature semiconductor

HVPE: hydride vapor-phase epitaxy

IBAD: ion-beam-assisted deposition

IMN: Institut des Matériaux Jean Rouxel

IR: infrared

ITRI: Industrial Technology Research Institute

ITU: Institute for Transuranium Elements

LANL: Los Alamos National Laboratory

LCD: liquid-crystal display

LDL: low-density liquid

LED: light-emitting diode

LLNL: Lawrence Livermore National Laboratory

MBE: molecular-beam epitaxy

MEMS: microelectromechanical systems

MFM: magnetic force microscopy

MIT: Massachusetts Institute of Technology

MPI: Max Planck Institute

MRI: magnetic resonance imaging

MOCVD: metalorganic chemical vapor deposition

MOD: metalorganic decomposition

MOS: metal oxide semiconductor

NASA: National Aeronautics and Space Administration

NCSU: North Carolina State University

NIH-NIBIB: U.S. National Institutes of Health,

National Institute of Biomedical Imaging and Bioengineering

NIH-NIDR: U.S. National Institutes of Health, National Institute of Dental Research

NIST: National Institute of Standards and Technology

NMR: nuclear magnetic resonance
NREL: National Renewable Energy

Laboratory

NSF: U.S. National Science Foundation

OHD: one hydrogen atom

ONR: Office of Naval Research

ORNL: Oak Ridge National Laboratory

OSG: organosilicate glass

OTFT: organic thin-film transistor

PEG: poly(ethylene glycol)

PEMFC: proton exchange membrane fuel cell

PLD: pulsed laser deposition

PLZT: lanthanum-doped lead zirconium titanate

PPV: poly(phenylene vinylene)

PSU: The Pennsylvania State University

PV: photovoltaic

PZT: lead zirconium titanate

QC: quasi-crystal

QD: quantum dot

R\&D: research and development

RAM: random-access memory

rf: radio frequency

RGB: red-green-blue

SNL: Sandia National Laboratories

STM: scanning tunneling microscopy

STV: streptavidin

SWNT: single-walled carbon nanotube

TFT: thin-film transistor

UC: University of California

UCLA: University of California-Los Angeles

UIUC: University of Illinois-Urbana-Champaign

UMIST: University of Manchester Institute of

Science and Technology

UV: ultraviolet

VCM: vertical composition modulation WPAFB: Wright-Patterson Air Force Base

YAG: yttrium aluminum garnet

YBCO: $\mathrm{YBa}_{2} \mathrm{Cu}_{3} \mathrm{O}_{7}$ 
said Seeman, include the extension of 2D results to $3 \mathrm{D}$ systems, and incorporation of DNA devices in 2D and 3D arrays.

Following earlier work in the area of nanofabrication in the 1990s with dippen nanolithography (DPN), C. Mirkin (Northwestern) has now achieved directwrite linewidths of $10 \mathrm{~nm}$ resolution, as reported in Symposium M. In DPN, a reagent such as DNA on an AFM tip is transferred to a substrate through a meniscus of water condensed on the tip. By combining massive parallel arrays of up to 10,000 dip pens with a variety of molecular "inks," the technology has potential as a mass production process. This makes it an ideal technique for combinatorial screening of materials systems. To control the size of deposited dots of materials, Mirkin and his co-workers have used "electronic whittling," which involves the application of electrical pulses to desorb atoms at edge sites preferentially. Organic nanostructures have been whittled from diameters of $300 \mathrm{~nm}$ down to $150 \mathrm{~nm}$ using this technique. Gold dots have been reduced to $45 \mathrm{~nm}$ in diameter, and gaps in linear gold structures as small as $12 \mathrm{~nm}$ have been produced in a controlled manner. Some applications currently under investigation include nanoprinted catalysts, ultrahigh-density oligonucleotide and proteomic arrays, molecular electronics, and pattern generation for cryptography.

Not only are AFM tips used to print patterns and to perform atomic imaging, but as W.L. Hughes (Georgia Tech) reported in Symposium L, they can also serve as jackhammers on the nanoscale to cut $\mathrm{ZnO}$ nanobelts to the required length to form nanocantilevers.

"AFM is a critical tool for manipulation and modification of nanostructures," Hughes said. Nanobelts are long, ribbonlike nanostructures of semiconducting oxides, with dimensions ranging from 50 $\mathrm{nm}$ to $1 \mathrm{~cm}$ in length and $2 \mathrm{~nm}$ to $1 \mu \mathrm{m}$ in width. Most important, they are flexible, single-crystal materials. Their size is many times smaller than cantilevers available using current technology; by decreasing the cantilever length, its sensitivity to vibration or deflection increases. While Hughes and co-workers have been working with $\mathrm{ZnO}$, other oxides such as $\mathrm{Ga}_{2} \mathrm{O}_{3}, \mathrm{SnO}_{2}, \mathrm{PbO}_{2}$, and $\mathrm{In}_{2} \mathrm{O}_{3}$ can be used as well. The advantage of $\mathrm{ZnO}$ is that it is piezoelectric. The belts are formed by vaporizing oxide powders and depositing them on a substrate. Individual nanobelts can be removed from the substrate using an AFM tip, then dimensional modifications can be made by using the tip in "tapping mode" to fracture the belt. The researchers were

\section{Von Hippel Presentation Confirms the Best Things Come in Small Packages}

The Von Hippel Award, the Society's highest honor, was presented to Julia R. Weertman of Northwestern University during the awards ceremony at the 2003 MRS Fall Meeting. Weertman then gave her Von Hippel presentation, "The Search for Small: From Grain-Boundaries Cavities to Nanocrystalline Metals."

Spanning her research career in materials, Weertman covered her early work on grain-boundary cavitation and voids in metals subject to fatigue and creep and her later work on nanocrystalline metals, in which she discussed the role of dislocations at very small grain sizes. Simulations by other researchers and the observed lack of strain hardening suggest that dislocations nucleate at the grain boundaries but are absorbed at neighboring boundaries, leaving no dislocation debris.

Weertman's group has performed in situ straining of nanocrystalline copper and, more recently, nanocrystalline nickel films. In the Ni films, dislocations were seen in grains as small as $10 \mathrm{~nm}$; however, there was no clear evidence of grain-boundary sliding. Deformation at this grain size appears to occur mainly by dislocation activity.

Weertman said that while nanocrystalline metals show great promise for use as high-strength materials, synthesis methods need to be radically improved.

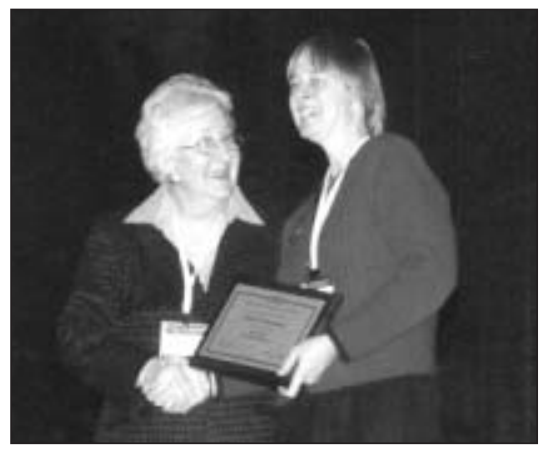

Julia R. Weertman (left) of Northwestern University is presented with the Von Hippel Award by 2003 MRS President Merrilea J. Mayo (GUIRR, National Research Council) during the MRS awards ceremony. able to place $\mathrm{ZnO}$ nanobelts across two gold electrodes, then anneal the system to embed the nanobelts into the gold, proving that devices can be made. Nanobelts have potential applications as physical, chemical, and biological sensors.

Strides made in materials and devices for smart systems were revealed in Symposium D. A technological fusion of sensor/actuator materials and MEMS appears to be key in the development of a multifunctional device and its application in smart systems. In the area of solid-state actuator materials, magnetic field-induced shape-memory alloys (e.g., NiMnGa, FePd, and $\mathrm{FePt}$ ) have been attracting attention as possible materials for magnetostriction. Although striction of $>3 \%$ has been demonstrated in single crystals, the stress load level for them was still as small as several MPa. K. Inoue (Univ. of Washington) suggested the high possibility of the application of an FePtPd system. On the other hand, M. Taya (Univ. of Washington) presented the composite-type actuator design combining iron and a superelastic shape-memory alloy that raised stress load durability. In regard to conventional magnetostrictive materials, Y. Furuya (Hirosaki Univ.) discussed the rapid-solidified polycrystalline FeGa alloy, and Y.-C. Shu (Natl. Taiwan Univ.) discussed micromagnetic modeling for Terfenal-D film.

Significant progress in ferroelectric device technology was demonstrated in Symposium C, and in a joint session with Symposium E, presenters covered research in gate dielectrics for advanced MOS devices, piezoelectric effects, and ferroelectric gate transistors. Issues involving the heterostructure of Si substrates and oxide thin films were extensively discussed, and the thermal stabilities of these interfaces seemed to be the common theme. For industry experts thinking about MOS devices, noncrystalline phases are especially important because the leakage current through the film drastically increases if the film becomes polycrystalline. On the contrary, piezoelectric researchers tried to make heteroepitaxial oxide films on $\mathrm{Si}$ or $\mathrm{SrRuO}_{3}$ substrates because film performance would be enhanced if the orientations could be controlled. A thin $\mathrm{SrTiO}_{3}$ buffer layer on $\mathrm{Si}$, proposed by V. Vaithyanathan (PSU), makes it possible to grow high-quality single-phase oxide materials on Si. For realizing ferroelectric gate transistors, researchers have tried various ferroelectric materials in metal-ferroelectricinsulator-semiconductor structures. Guiding principles for materials selection have been accepted (e.g., small remanent polarization and a good interface 
between the film and $\mathrm{Si}$ ), but there seem to be no focused materials for this application. The only exception would be $(\mathrm{Sr}, \mathrm{Sm})_{0.8} \mathrm{Bi}_{2.2} \mathrm{Ta}_{2} \mathrm{O}_{9}$, as attempted by H. Saiki (Tokyo Institute of Technology).

Symposia AA and BB disclosed research results in the area of energy storage, generation, and transport, a topic of rising interest within both the government and among the general public. In Symposium AA on energetic/reactive nanomaterials, V. Colvin (Rice Univ.) focused on the environmental impact of nanomaterials, which has been receiving a lot of attention in the popular press. Since nanotechnology is developing at a feverish pace, such concerns are important to investigate, she said. While the effects of asbestos and biomaterials are better understood, engineered nanomaterials are in a different category.

For example, environmental results using $\mathrm{C}_{60}$ in an aqueous solution reveal that $\mathrm{C}_{60}$ forms stable colloids in water. M.-D. Cheng (ORNL) described recent work on the characterization of airborne ultrafine and nanometer-sized particles during energetic materials synthesis and testing in order to gain insight on airborne nanoparticles. Using the highexplosive research and development facility at Eglin Air Force Base (Florida), Cheng obtained quantitative measurements of physical and chemical attributes of the nanoparticles. Results were presented for conventional explosives, 15 $\mu \mathrm{m}$ particles, and $50 \mathrm{~nm}$ particles. The initial growth rate for the nanoparticles was very unusual, and there was a high level of the particles after $30 \mathrm{~min}$. These results have implications for biological toxicity in such atmospheres.

Another driver of materials research is the push to realize a hydrogen fuel economy. In the opening session of Symposium $\mathrm{BB}, \mathrm{Q}$. Wang (Zhejiang Univ.) said that the transformation of the energy system to the hydrogen economy is important for environmental protection, petroleum security, and the conservation of resources. He explained the recent history of the hydrogen program in China beginning in 1978, following the Cultural Revolution. Top scientists introduced prospects of the hydrogen economy during what Wang called the first of four periods of the program (1978-1985), when the production of hydrogen relied on electrolysis of water and metal hydride technology. The second period (19861997) saw the national demand for hydrogen, driving growth. Period 3 (1998-2008) is represented by the central government's support of a national program in this field for energy security, reduction of air pollu-

\section{Plenary Speaker Reveals Relevance of Semiconductor Research for National Security}

Plenary speaker Darryl L. Smith of Los Alamos National Laboratory presented his talk on "Electronic Properties of Inorganic and Organic Semiconductors: Application to National Security Needs." Semiconductors are being researched for the area of infrared detectors and sources, including (Ga,In)Sb/InAs strained-layer superlattices as IR materials; gamma-ray detectors, including charge-collection devices, scintillators, and quantum dot/organic semiconductors as gamma detectors; and chemical and biological sensors, including organic FETs. Inorganic semiconductors - crystalline in structure-have strong bonding and a wide bandgap. They can be used for doping, alloying, and creating heterostructures. One of the problems with inorganic semiconductors is that they require high-quality materials since they are very sensitive to impurities and crystal defects. Organic semiconductors, on the other hand, are disordered, have weak intermolecular bonding, and localized states. Design options include chemical substitution and self-assembly. A major advantage of organic semiconductors is that they can be economically processed in large areas at low temperatures. Smith said that the differences in the basic electronic structures of the two types of semiconductors result in distinct but complementary physical properties.

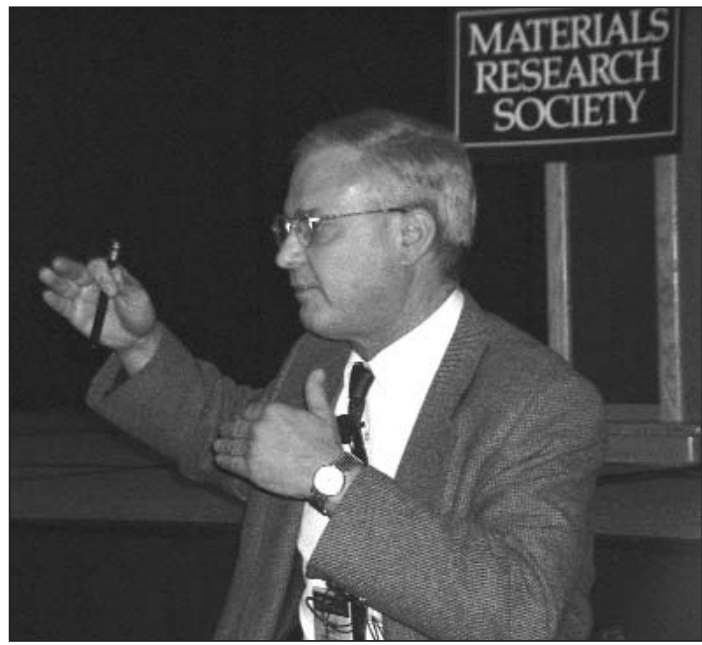

Plenary speaker Darryl L. Smith of Los Alamos National Laboratory discussed electronic properties of inorganic and organic semiconductors and their application to national security needs. tion in the cities, and for future competitiveness in the automobile industry. The program's goal in the auto industry is to create electric and hybrid cars powered by fuel cells. Research also emphasizes PEMFC-powered scooters and bicycles, vehicles commonly used in China. Wang delineated a proposal that went to the provincial government of Zhejiang (Period 4), in which emphasis is placed on supporting progress in both the $R \& D$ for hydrogen use and the hydrogen infrastructure, simultaneously.

Likewise in the United States, the National Hydrogen Storage Project is focused on R\&D for metal hydrides, chemical storage, carbon materials, and the development of new materials and processes. C.J. Read, of the Office of Hydrogen, Fuel Cells, and Infrastructure Technologies in the Department of Energy (DOE), said the department requested $\$ 150$ million over five years, which is subject to congressional appropriations. Significant achievement is expected several years from now. For example, the DOE dedicated Phase 1 from now through 2015 for R\&D to overcome key technology hurdles. The department's targets can be viewed on their Web site at www.energy.gov. The DOE is mainly concentrating on hydrogen storage as an alternative fuel for automobiles, with the goal of achieving 300 miles/tank.

According to S.R. Ovshinsky, president and CEO of Energy Conversion Devices, "the hydrogen economy is here" - a statement he backed up with a display of Ovonic products, including a shingle from a solar-cell panel and a very lightweight PV thin film. The PV thin film has been tested on the space station and is planned for space use, such as in satellites. It generates $2000 \mathrm{~W} / \mathrm{kg}$. Ovshinsky described how hydrogen as a fuel could be stored in a solid hydride and used instead of highpressure or liquid hydrogen.

For further details on the technical content of the Meeting, see the following symposium summaries. Proceedings are available on-line at www.mrs.org. 


\section{Women Fall Behind Men in the Technical Work Force}

Even though women enter the technical work force at a slightly higher average salary than their male counterparts and initially attain leadership positions (as determined by the number of people reporting to them) equivalent to males, after less than five years in the work force, average salaries for women fall below those for men and the average number of people reporting to females remains almost constant while the number of direct reports for males increases continuously. These are the statistics Nancy Jackson showed at the Women in Materials Science and Engineering Breakfast held midweek at the MRS Meeting. Jackson, manager of the Chemical and Biological Sensing, Imaging and Analysis Department at Sandia National Laboratories in Albuquerque, was the featured speaker at the breakfast. In her presentation, "After All These Years ... What are the Studies Saying About Women in the Technical Work Force Today?," Jackson said that there was probably no one single reason for this difference in achievement, but rather that marginalization of women in the technical work force "comes in many small pieces that accumulate over time [over a career]." Many times, "men get a small but real advantage in different workplace situations and that advantage accumulates over time," she said. To attain greater equity in the technical community, Jackson suggested that women become more actively involved in mentoring and become more visible in technical societies, among other strategies.

Micro- and Nanotechnologies March On (See MRS Proceedings Volume 782)

Symposium A commenced with a packed audience for a tutorial presented by M. Madou (UC-Irvine), D. Polla (Univ. of Minnesota), and C. Montemagno (UCLA) titled "Icarus Revisited," focusing on the convergence of nano- and biotechnologies. Invited speakers summarized state-of-the-art work in areas spanning from biomimetic self-assembly (G.D. Bachand, SNL), poly-SiGe for MEMS (A. Witvrouw, IMEC), carbon nanotube field emitters (N. de Jonge, Philips Research), Ni and Ni-Fe for LIGA (K. Bade, IMT), effects and aging of monolayer lubricants on MEMS (M. Dugger, SNL), and thin-layer transfer fabrication techniques (B. Aspar, Tracit Technologies).

Contributed presentations and posters bridged many areas of microfabrication, nanosynthesis, new materials, small-scale mechanics, and tribology. This year's symposium included many presentations on combining micro- and nanofabricationsuch as using e-beam and photolithography to pattern islands of catalyst to direct the local formation of nanotubes. Several groups presented work on polymers and polymer fabrication techniques as well, including work on polymer deposition for dielectric control and cell patterning. The poster session for this symposium covered work ranging from basic studies of mesa formation to nanofabrication and hot embossing.

\section{Passive Components Critical in Materials, Integration, and Packaging Issues for High-Frequency Devices (See MRS Proceedings Volume 783)}

Symposium B grouped together the var- ious issues of materials technology that are key factors for the advancement of highfrequency devices (e.g., mobile phones). Passive components constitute $70-90 \%$ of the number of components, volume, and costs, which are of concern when increasing the performance of the devices. The field advances primarily by improving current applied technologies. Impressive progress has been reported in the field of low-temperature co-fired ceramics. Advancements in low-shrinkage processing allow for making more complex structures (C.R. Needes, DuPont, and G.L. Messing, PSU). A growing understanding of microstructure-property relationships in perovskites is leading to new materials compositions with lower firing temperatures for microwave ceramics with high quality factors (P.K. Davies, Univ. of Pennsylvania). Advancement in the field also arises from newly exploited materials phenomena. The tunability of the permittivity of ferroelectrics potentially allows low-cost solutions for frequency tuning and phase shifters. The crucial question is whether ferroelectric thin films may meet the lowloss/tuning requirements (N. Setter, EPFL) and how $(\mathrm{Ba}, \mathrm{Sr}) \mathrm{TiO}_{3}$ device performance in particular improves by optimizing integration and design (A.I. Kingon, NCSU). A third path deals with the development of new integration platforms and packaging concepts, such as tapes with embedded high- $\kappa$ dielectrics and photoformable (photoimageable) and platable conductors, or platforms compatible with semiconductor and MEMS processing. Flexible copper tapes coated with $\mathrm{BaTiO}_{3}$ thin films exhibiting $\kappa=3000$ have been developed (J. Ihlefeld, NCSU). Highresistive silicon substrates can be improved to meet microwave compatibility and were shown to be suited as integration platforms for thin-film resistorinductor-capacitor networks and MEMS rf switches (J. van Beek, Philips, IMEC). Interesting concepts and perspectives for complex system-in-packaging using chipsized packaging were presented (H.A.C. Tilmanns, IMEC). High-density packaging has been achieved by means of capacitive coupling of interconnects (P.D. Franzon, NCSU). In a fourth path, passive components are being integrated directly onto digital signal processing chips. On-chip capacitors fall into this category, as well as above-chip bulk acoustic wave devices based on piezoelectric thin films such as $\mathrm{AlN}$ and $\mathrm{ZnO}$. Highly textured AlN films grown at low temperatures have exhibited improved properties, compared with previously published data (H.P. Loebl, Philips and F. Martin, EPFL).

Symposium Support: DuPont, EPCOS OHG, and Philips Research.

\section{Novel Ferroelectric Thin Films Show Interesting Properties and Potential for Integration}

\section{(See MRS Proceedings Volume 784)}

Significant progress in ferroelectric device technology was demonstrated in Symposium C, along with continuing developments in novel oxide materials, techniques to characterize their properties, and the fundamental understanding of ferroelectricity in thin films. Several presentations highlighted advances made in FeRAMs. Presenters addressed a variety of subjects, including issues of materials integration, metal oxide electrode utilization, the effect of stress on capacitor properties, and long-term reliability. J.G. Lisoni (IMEC) addressed progress in the fabrication of "pseudo- $3 \mathrm{D}^{\text {" }} \mathrm{SrBi}_{2} \mathrm{Ta}_{2} \mathrm{O}_{9}$ capacitors over $\mathrm{W}$ contact plugs using prepatterned $\mathrm{TiAlN} / \mathrm{Ir} / \mathrm{IrO}_{2} / \mathrm{Pt}$ bottom electrodes that allows successful $700^{\circ} \mathrm{C}$ SBT crystallization with controllable TiAIN lateral oxidation. J.S. Cross (Fujitsu) described interactions of various oxide electrodes (e.g., $\mathrm{IrO}_{2}$ and $\left.\mathrm{SrRuO}_{3}\right)$ with $\mathrm{Pb}(\mathrm{Zr}, \mathrm{Ti}) \mathrm{O}_{3}(\mathrm{PZT})$ and $(\mathrm{Pb}, \mathrm{La})(\mathrm{Zr}, \mathrm{Ti}) \mathrm{O}_{3}$ (PLZT) FRAM capacitors, their reliability, and switching issues, attempting to explain polarization losses and their related mechanisms. In addition, B.-K. Moon (Infineon) reported on control of the crystallographic orientation of PZT films on $\mathrm{Ir} / \mathrm{IrO}_{2} / \mathrm{Pt}$ (111) bottom electrodes using $10 \mathrm{~nm}$ thin Ti/PZT seed bilayers, allowing the achievement of PZT capacitors (with $\mathrm{SrRuO}_{3} / \mathrm{Pt}$ top electrodes) with $Q_{\text {sw }}$ of $41.2 \mu \mathrm{C} / \mu^{2}$ and fatigue-free behavior up to $10^{10}$ switching cycles.

There were also several papers by 
ULVAC, Inc. (K. Suu, T. Jimbo, and Y. Nishioka), highlighting its rf magnetron sputtering and MOCVD techniques for FeRAM integration. T. Furukawa (R\&D Association for Future Electron Devices, Japan) presented an all MOCVD approach to fabricate a ferroelectric capacitor using $\mathrm{Ru}$ films for electrodes and $\mathrm{Bi}_{4-x} \mathrm{La}_{x} \mathrm{TiO}_{3} \mathrm{O}_{12}$ ferroelectric thin films.

Advances in the deposition of ferroelectric thin films were also highlighted, with several groups demonstrating high piezoelectric coefficients $d_{33}$ in both Pb-based and Bi-based films. The use of ferroelectric thin films for a variety of piezoelectric applications was also described, with a combined survey of new materials (e.g., $\mathrm{Bi}_{4-x} \mathrm{Pr}_{x} \mathrm{~T}_{3} \mathrm{O}_{12}$ ) and growth control for a high degree of orientation along the major polar axis on $\mathrm{Ir} / \mathrm{Si}$ and $\mathrm{IrO}_{2} / \mathrm{Si}$ substrates for this application provided by H. Matsuda (AIST, Japan). The investigation of epitaxial films deposited on a wide variety of substrates is also an area of active research by numerous groups. Sitecontrolled nucleation of self-assembled PZT crystallites has been reported by P. Muralt (EPFL). Significant progress was made on the deposition of ferroelectric thin films on $\mathrm{Si}$ in suppressing the $\mathrm{Si}$ oxidation of the interface. H.N. Lee (ORNL in collaboration with MPI) demonstrated that high-pressure PLD is an excellent technique for growing superlattices $\left(\mathrm{BaTiO}_{3} / \mathrm{SrTiO}_{3} / \mathrm{CaTiO}_{3}\right)$ that are compositionally asymmetric. Research in the area of strain effects in thin films on ferroelectric properties was also on display. J. Wang (Univ. of Maryland) presented work on the effect of strain on the ferroelectric properties of multiferroic $\mathrm{BiFeO}_{3}$ films having enhanced properties as compared with the bulk. Strain in the films was controlled by changing the structure of the material as a function of substrate orientation. A simple theoretical model was developed by A.K. Tagantsev and P. Muralt (EPFL) to explain the shape of the piezoelectric coefficient dependence with the applied electric field for the case of nonferroelastic switching in ferroelectric materials.

Some presentations addressed the use of high-permittivity materials for a variety of capacitor applications. Materials such as $(\mathrm{Ba}, \mathrm{Sr}) \mathrm{TiO}_{3}$ (BST) are of particular interest for use as decoupling capacitors. The fundamental mechanisms of BST steady-state leakage currents were highlighted by H. Schroeder (IFF-EKM, Jülich). High-frequency applications (e.g., rf voltage-tunable devices) require the use of high-conductivity metallization (low-loss electrode schemes). Significant progress on integrating BST devices with $\mathrm{Cu}$ foils (B. Laughlin, NCSU) and other metal films by utilization of extremely low $\mathrm{O}_{2}$ partial pressure anneals has been demonstrated. The high-frequency properties of $(\mathrm{Ba}, \mathrm{Sr}) \mathrm{TiO}_{3}$ thin films deposited on various low-loss substrates were also discussed in several presentations.

Symposium Support: Aixtron AG; Gennum, Canada; Kojundo Chemical Lab., Japan; Symetrix; Tegal; and ULVAC, Japan.

\section{Polymers Drive Smart Systems to Human/Materials Interface (See MRS Proceedings Volume 785)}

Symposium D addressed materials and devices for smart systems, specifying a future direction in human/materials inter- faces and systems. As devices become small and very light, they may be implemented in living bodies by the combination of thin film, MEMS, smart actuator/ sensor technology. Development of a highperformance solid-state actuator relies on optimal control of high-performance polymers based on a self-organization mechanism, nano-domain morphology, carbon nanotube composite, and a submicrometer crystalline structure. In the area of electroactive polymers (EAPs), J. Su (NASA) pointed out the need for electromechanical properties of elastomers that can be tailored and optimized by molecular engineering (chemically) and morphological

\section{Small Devices Build on Sharp Oxide/Semiconductor Interfaces (See MRS Proceedings Volume 786)}

Interfaces between oxides and semiconductors are becoming increasingly important to a number of emerging applications and are more critical as devices scale into the nanometer regime. Several presentations in Symposium E showed that even complex oxides can be grown epitaxially on semiconductors with atomically sharp interfaces, enabling combinations of the wide range of functionalities of oxides with semiconductor devices. The device potential of such "smart transistors" were described by J. Singh (Univ. of Michigan), whose device simulations revealed the superior sensor properties that could be achieved by replacing the gate oxide of a transistor with a polar material (see Figure). For optimal performance, the functional material should be thin $(\sim 20 \AA)$, so that the device has excellent performance even if the interface with the semiconductor contains many defects.

Many of the presentations covered recent advances in incorporating new gate dielectrics in Si-based technologies. In addition, emerging applications for oxide/compound semiconductor interfaces were presented. The symposium began

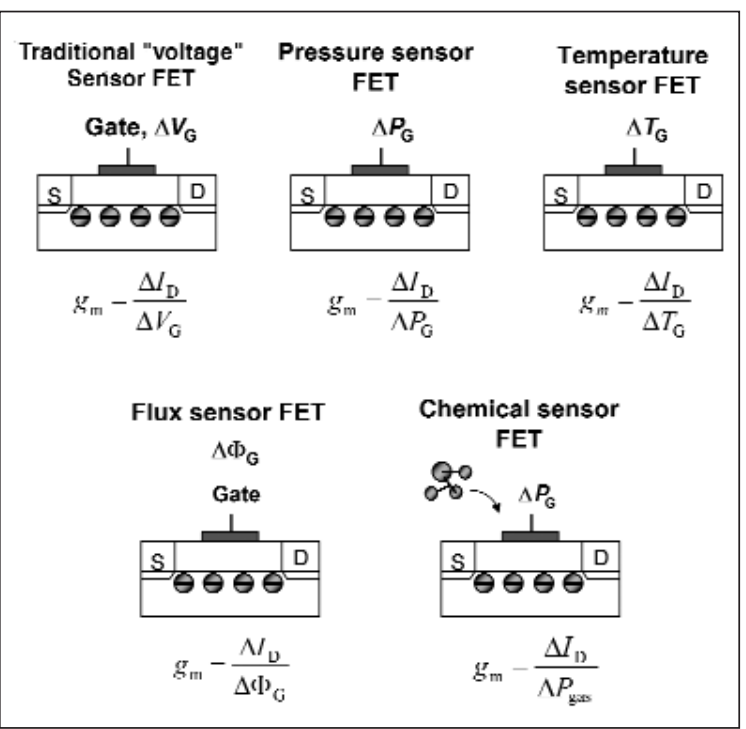

Figure. Generic heterostructures for multifunctional FET devices proposed by J. Singh (Univ. of Michigan). These make use of either ultrathin polar oxides on semiconductors or ultrathin magnetic oxides on semiconductors. $S=$ source, $D=$ drain, $\mathrm{G}=$ gate, $\mathrm{I}=$ current, $\mathrm{V}=$ voltage, $\mathrm{P}=$ pressure, $\mathrm{T}=$ temperature, $\Phi=$ flux, and $\mathrm{g}_{m}=$ transconductance. with a focus on the characterization of interfaces and oxides. Physical characterization is becoming increasingly challenging in Si CMOS devices as novel oxides are incorporated as ultrathin layers. The development of new techniques such as inelastic electron tunneling spectroscopy was reported. In addition to new experimental methods, theory is becoming an increasingly important tool in providing an understanding of the atomic structure and properties of novel oxide semiconductor interfaces. One session dealt with calculations of the atomic structure of interfaces between amorphous and crystalline oxides and $\mathrm{Si}$ as well as calculations of oxide dielectric properties.

Symposium Support: ARO. 
control (physically). Computational modeling, EAP composites, and polymer-based MEMS were also introduced. The technological fusion of sensor/actuator materials and MEMS is already indispensable in smart device development. In terms of structure, researchers expect to see an increase in studies on active vibration control, active and noncontact nondestructive evaluation, and structural health monitoring with wireless sensing technology.

Symposium Support: ARO and Hirosaki Univ.

\section{Shape-Memory "Springs" Mend the Body While Cell-Seeded Scaffolds Guide Organ Regeneration (See MRS Extended Summaries EXS-1)}

Internationally renowned leaders in the field of biomaterials kicked off Symposium $F$ in a session titled "Overview and Challenges in Biomaterials," providing an introduction to the possibilities and challenges in tissue engineering. R.S. Langer (MIT) presented three types of future techniques and examples from work done by members of his research group. The first is a family of shape-memory biocompatible polymers synthesized using dioxanone and E-caprolactone. Langer showed a video of a string of these polymers at room temperature that converts into a springlike coil when dropped into $37^{\circ} \mathrm{C}$ water. He also showed a video of a loose knot that ties itself when dropped into water at body temperature. Both of these materials have the potential to be used as human implants. The second example involved the creation of a reversibly switching surface that dynamically changes from hydrophobic to hydrophilic and back, using self-assembled monolayers of molecules. The third example was transdermal photopolymerization, wherein light was used to penetrate skin and form/shape polymers in vivo. Langer also discussed the creation of blood vessels and spinal cord segments using neuronal stem cells.

A. Atala, from Children's Hospital in Boston, presented data from his laboratory's surgical successes, most notably the implantation of tissue-engineered bladders into patients, using an approach that marries materials engineering with the body's own regenerative capacities. These artificial bladders are virtually indistinguishable from native bladders. Approximately 100 human patients have had strictured urethras replaced by tissue scaffolds seeded with their own cells, resulting in the growth of a new, fully functioning section of urethra of normal diameter. In animal trials, the first litter of normal, healthy rabbits was recently delivered from an engineered uterus. A great deal of this success comes from the use of autologous cells-those taken from the patient, seeded onto the scaffold, and placed back into the patient's own body. Such a strategy avoids the organ-rejection mechanism common with donor organs. Another reason for the success is that it uses the body as the ultimate bioreactor. Instead of trying to grow cells in vitro in solutions containing the chemicals and growth factors deemed necessary for their survival and multiplication, the scientists place the seeded scaffold back into the body, which has precisely the right environment for the growth and differentiation of cells. The body knows what to do from there, growing the cells and providing the necessary blood vessels and nerve tissues to the organ.

Other key presentations touched on critical issues such as inflammation, infection, wound healing, and the challenges associated with understanding the complexity of the biological response. Other sessions covered 3D constructs, natural and artificial polymers, new technologies, and surface analysis and engineering.

Symposium Support: Asylum Research, Boston Scientific, Ethicon/Johnson and Johnson, Genzyme, Guidant, and The Whitaker Foundation.

\section{Molecular Imprinting Makes Its Mark (See MRS Proceedings Volume 787)}

Aspects of molecular imprinting were covered in Symposium G, including catalysis, combinatorial and computational methods, sensors, hydrogels, and drug discovery. The topic attracted international attention with contributed and invited talks from Japan, Germany, Sweden, the United Kingdom, and the United States.

Symposium Support: MIP Technologies AB, NSF, and Semorex.

\section{Bio-Inspiration Leads to Nanoscale Assembly and Direct Incorporation of Biological Matter}

\section{(See MRS Proceedings Volume EXS-1)}

Investigations of a variety of biological and bio-inspired materials designed to produce nanoscale patterning and organization were discussed in Symposium H. Several researchers described biological materials that direct the assembly of gold nanoparticles; others discussed the organization of functional groups in biological polymers and its effect upon their bioactivities. Similarly, researchers have explored the use of nonnatural peptide-inspired polymers with controlled functional-group patterning to mimic the structure and activity of natural antimicrobial polymers. On a larger scale, several groups have used natural folded proteins such as titin, fibronectin, and mussel adhesive proteins as inspiration for the development of novel biomaterials, including non-fouling PEG films. Other work detailed how small biological and bio-inspired molecules can direct their own self-assembly into structures with macroscale order. In work centered on the organization of nanoparticles, researchers now have the ability to create and manipulate systems on the nanometer scale. Furthermore, research on synthetic antimicrobial oligomers has shown the capability of synthetically mimicking the organization and functionality of biological molecules.

DNA nanotechnology is a bottom-up approach to the assembly of functional devices. This requires novel building blocks to incorporate a functional and structural hierarchy. M. Bajaj (MIT) described the creation of silica microspheres with one hemispherical face deposited with gold. Different surface chemistries-silane chemistry for the silica side and thiol chemistry for the gold side-were used to immobilize different DNA sequences on the two faces. These were then used for selective orthogonal assembly. Bajaj also described the creation and use of trifunctional particles. C.M. Niemeyer (Univ. of Dortmund, Germany) described a different technique for the self-assembly of oligomeric networks using streptavidin (STV) and DNA. These were used as model systems for ion-switchable nanoparticle networks. He also described DNA-directed immobilization for reversible and site-selective functionalization of solid substrates with metal and semiconductor nanoparticles. Niemeyer discussed specific examples including biochips, enzyme technology, and surface engineering.

The ability to mimic nature is most often limited by nature's vast complexity. As a result, those who wish to develop more complex biological systems have demonstrated a paradigm shift away from raw mimicry and toward incorporation of raw biology into synthetic systems. Increasingly, investigators are integrating the order and complexity of nature into synthetic materials to a synergistic effect and are exploiting natural biological templates to make more complex materials and systems.

Symposium Support: Degussa AG, Germany; GelTex Pharmaceuticals/Genzyme, USA; Henkel KGaA, Germany; and NIH-NIDR and NIH-NIBIB.

\section{Molecular and Organic Electronics Focuses on Interfaces and Electrical Contacts}

In the areas of molecular and of organic electronics, the issue of interfaces and electrical contacts is an emerging concern from the point of view of fundamental 
understanding (for both areas) and for practical developments (in the latter). Symposium J addressed the nature of the interfaces where a material normally described in terms of delocalized electrons meets one commonly described in terms of localized electrons. This leads to the question of how far accepted models for the metal/semiconductor or semiconductor/semiconductor interface can be applied in order to understand these interfaces and the devices based on them. After a somewhat stormy period in the development of the field of molecular and of organic electronics, it has become widely accepted that these models also apply in the area of molecular or moleculebased electronics.

Other issues discussed included how to make contacts to molecules, how molecules make electrical contact, and how such interfaces should be characterized experimentally and described theoretically. The effects of interface polarization and interface dipoles in the final equilibrated interface, and their implications for possible barriers for electronic transport, came up as well as the problem of exact chemical descriptions of these interfaces with the tools normally available.

\section{Light and Electrons Dance through Organic Devices}

Symposium K on functional organic materials and devices reported recent advances and new developments in the area of organic-based photonics, electronics, and optoelectronics. Among the highlights was the development of highefficiency tandem organic light-emitting devices (L.-S. Liao, Kodak). The new structure produced significant enhancement in light output over traditional devices. P. Ho (Cambridge) talked about the effects of high-quality polymer-polymer heterostructures on device performance. S. Vaidyanathan from M.E. Galvin's group at the University of Delaware showed a study on the effects of chemical architecture of PPV-based copolymers on device electroluminescence. Devices based on statistical copolymers performed much better than those based on alternating copolymers (up to $50 \%$ enhancement in luminescence efficiency). This work showed the possibility of polymeric devices having high external quantum efficiency and brightness at low applied voltage. Universal Display Corp. presented its latest development in the rapidly growing area of phosphorescent organic light-emitting devices. Some of the company's newly developed materials allow for the fabrication of devices with extended lifetimes over previously reported data.
T. Someya (Univ. of Tokyo) presented his team's findings on using screen-printing techniques to print silver-based paste and pattern it to dimensions as low as $20 \mu \mathrm{m}$ for application in organic-based transistors. P. Calvert, with G.E. Jabbour's group at the University of Arizona, presented its latest findings on modifying the sheet resistivity of polymeric anodes using inkjet printing techniques. Gray-scale sheet resistivity can be obtained with this method, leading to the fabrication of a variety of light-emitting structures. These include photographs on flexible plastic-, paper-, and textile-based substrates. New promising hybrid materials based on octaphenylsilsesquioxane nanobuilding blocks with high transition temperature and excellent stability were presented by a research team of the University of Michigan. These materials are very promising candidates for light-emission and photovoltaic applications. Other areas covered included photovoltaics, thin-film transistors, molecular electronics, and novel nanothick organic and hybrid memory storage devices. Talks related to interfaces in organic-based devices were presented under a joint session with Symposium J.

\section{Industry Examines Applications of Nanostructured Materials (See MRS Proceedings Volume 788)}

A large number of presentations by small and large companies, in Symposium L, featured novel applications for nanoma-

\section{MRS Medalists Discuss Areas of Exchange Bias, Biologically Inspired Materials}

Ivan K. Schuller of the University of California-San Diego presented his MRS Medal talk on exchange bias in magnetic materials. After a brief introduction to ferromagnetism and the $\mathrm{M}-\mathrm{H}$ hysteresis loop, Schuller reiterated that the reversal mode is the same for both sides of the hysteresis loop in all ferromagnets. However, when a ferromagnet is in contact with an antiferromagnetic, an "exchanged-biased" configuration, interesting phenomena are observed: The hysteresis loop shifts to one side, the width (coercivity) increases, and the reversal becomes asymmetric. To understand these results, Schuller emphasized the role of spin orientation, the cooling field, and defects in the antiferromagnetic layer. He also listed, for new researchers, interesting challenges yet to be resolved.

In his MRS Medal presentation, C. Jeffrey Brinker of Sandia National Laboratories/University of New Mexico focused on the self-assembly of biologically inspired complex functional materials. His goal has been to emulate biological sys-

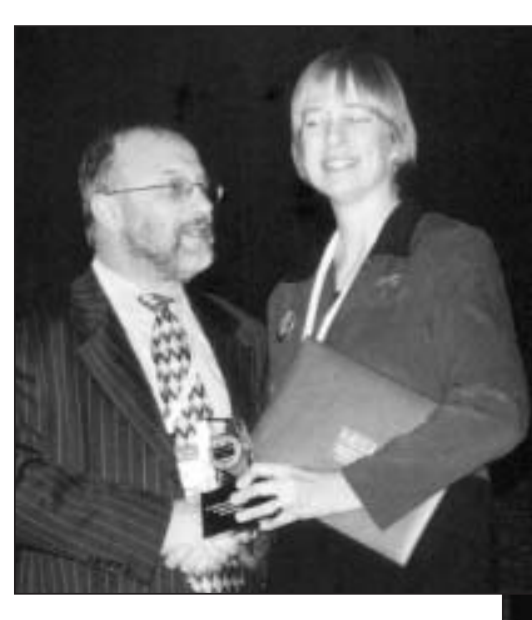

tems in order to develop new properties in materials by means of their nanostructure and integration on the meso- and macroscales. The principal challenge in this field is controllably mixing and organizing organic and inorganic materials on the nanoscale.

Ivan K. Schuller of the University of California-San Diego (left) receives the MRS Medal from 2003 MRS President Merrilea J. Mayo (GUIRR, National Research Council) during the awards ceremony.

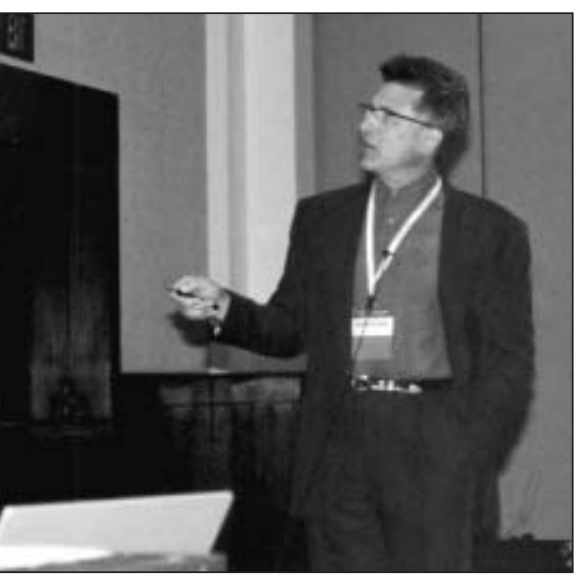

C. Jeffrey Brinker of Sandia National

Laboratories/University of New Mexico presents his MRS Medal talk on the self-assembly of biologically inspired complex functional materials. 
terials. Applications broadly covered microelectronics, imaging, pharmaceuticals, sensors, fuel cells, and chemical conversions and catalysis. Along with applications, the symposium showcased a variety of topics on continuous nanophase and nanostructured materials, spanning experimental work, theoretical modeling, and characterization. Synthesis of some novel structures ranged from nanoparticles (equiaxed to acicular) to ribbons, tubes, rods, and wires using chemical and physical methods.

Symposium Support: Advanced Nano Products, Korea; Cabot Microelectronics; NanoProducts; and NSF.

\section{Nontraditional Approaches to Patterning Introduced} (See MRS Extended Summaries EXS-2)

The ability to pattern materials into well-defined structures plays an important role in fields such as physics, chem- istry, biology, and engineering. Structures with critical dimensions on the nanoscale have been shown to exhibit interesting and potentially useful phenomena that include quantized excitation, Coulomb blockade, single-electron tunneling, and metal-insulator transition. Micrometersized structures, on the other hand, have been widely explored for use in fabricating electronic devices, photonic components, display units, sensors, and MEMS,

\section{U.S. Funding for Materials Research: Idea- and Goal-Driven Opportunities}

Four representatives presented seminars on U.S. government funding opportunities in materials research. Among the goaldriven opportunities came information from the Department of Homeland Security (DHS) and the Office of Naval Research (ONR). Idea-driven opportunities, including support of unsolicited proposals, reside in National Science Foundation (NSF) and Department of Energy (DOE) programs.

Keith B. Ward, program manager for Chemical and Biological Countermeasures in DHS, gave an overview of the DHS organizational structure and then honed in on the Homeland Security Advanced Research Projects Agency (HSARPA), one of four offices under the Science and Technology Directorate.

Currently, there is almost no money available for basic research. For the first five years, $90-95 \%$ of funds will be geared toward immediate needs - mature technologies that can have real impact in the short-term. One focus, supported through technical support working groups, is on rapid prototypingessentially, systems that can be put together from completed components and then quickly taken into the field for testing.

Ward said the role for materials science lies in providing new materials that improve the sensitivity and selectivity of sensors, enhance secure communications, and provide personal protection against chemical, biological, kinetic, and radiation threats. Focusing on detecting threats and protecting the public from those threats adds an interesting twist to DHS. It leads to the requirement for "zero" false alarms, so that citizens neither panic nor grow complacent, coupled with affordable and flexible technologies that match regional needs and resources.

FY 2004 funding for the whole S\&T Directorate is $\$ 874$ million, divided among HSARPA; the Office of Plans, Programs, and Budgets; the Office of Research and Development; and the Office of Systems Engineering and Development. Funding through various mechanisms is available to small and large businesses,

\section{Government Funding Information} in Materials Research

Department of Energy (DOE) www.science.doe.gov/bes

Department of Homeland Security (DHS)

www.dhs.gov

National Science Foundation (NSF) www.nsf.gov

Office of Naval Research (ONR) www.onr.navy.mil encouraged to complete full proposals. Ward stressed the department's eagerness for a dialogue with the community, but with only seven program managers in place out of an anticipated need for 70, some extra patience may be required.

"The Office of Naval Research is the only U.S. funding agency created by public law," said Lawrence Kabacoff. ONR's main customer, he said, is the U.S. Navy, and while grant proposals are not peer-reviewed, they are intensely managed by a small cadre of professional program officers. Overall, \$60 million is available for materials, with one of the grand challenges designated as "Naval Materials by Design." Kabacoff highly recommends that researchers speak with the program officer in their field before submitting a proposal.

Robert Gottschall gave an overview of the DOE Office of Basic Energy Sciences (BES) and various possibilities for funding. Three aspects of the BES program are support of (1) fundamental science that addresses the DOE mission, (2) scientific user facilities and advanced research instruments for use by the national scientific community, and (3) stewardship of DOE-owned research institutions.

Gottschall described mechanisms by which BES funds materials research at universities and DOE laboratories, including proposal submission and peer-review procedures. He emphasized that BES supports idea-driven research that offers innovative and bold ideas that will yield cutting-edge science.

He also discussed two recent workshops that were conducted by BES. One assessed basic research needs for a secure energy future and may be accessed at http://www.sc.doe.gov/bes/BESAC/ Basic_Research_Needs_To_Assure_A_Secure_Energy_Future_ FEB2003.pdf, and the other assessed basic research needs for hydrogen production, storage, and use and may be accessed at http:/ / www.sc.doe.gov/bes/hydrogen.pdf.

Lance Haworth of the Division of Materials Research (DMR) at NSF discussed the extent of funding available for grants and described the different types of grants in materials research and education, including individual-investigator awards, focused research groups, centers, instrumentation grants, and user facilities. He described other programs, such as those within the Office of Special Programs in DMR, through which one of the recent thrusts has been international activities and cooperation in materials. He also outlined opportunities in nanoscale science and engineering, and opportunities for developing midscale instrumentation needed in materials research and for enhancing materials programs at minority institutions. In his overview of the criteria NSF uses for reviewing proposals, Haworth emphasized intellectual merit as well as broader impact of the proposed work.

All four representatives recommended visits to their Web sites for more information. 
as well as lab-on-chip systems. In these applications, patterning represents the first and one of the most significant challenges to their realization. Compared to conventional methods such as photolithography and e-beam writing, nontraditional techniques (e.g., soft lithography and the so-called bottom-up approach) may promise a more attractive strategy for the formation of patterned structures in terms of cost, throughput, and potential for large-scale production. Symposium M focused on four themes: (1) unconventional approaches to patterning (e.g., soft lithography, embossing, dip-pen lithography, and scanning probe lithography); (2) selfassembly of building blocks with critical dimensions in the nanometer to millimeter range (e.g., surfactants, polymers, colloidal particles, nanorods, and nanowires); (3) 3D lithography using two-photon absorption and optical interference; and (4) new concepts for micro- and nanoscale electronic, photonic, magnetic, and biofunctional structures, devices, or systems.

G.M. Whitesides (Harvard) discussed some recent developments and applications in soft lithography. P. Alivisatos (UC-Berkeley) described a new route to core-shell nanostructures and a templatedirected strategy for assembling nanoscale building blocks into well-defined arrays. C. Mirkin (Northwestern) illustrated how dip-pen nanolithography can be used to fabricate various types of functional nanostructures. E.L. Thomas (MIT) gave some perspectives in hierarchically ordered multicomponent nanocomposite materials. J. Rogers (UIUC) showed how near-field optical lithography could be used to generate long-range ordered 3D nanostructures. E. Delamarche (IBM, Zurich) discussed the use of microcontact printing in fabricating the arrayed TFTs for LCDs. M.M.J. Decre (Royal Philips Electronics, The Netherlands) demonstrated a method (the wave printer) for carrying out microcontact printing over very large areas. W. Huck (Cambridge) discussed the use of microcontact printing for high-resolution fabrication. H. Yang (Univ. of Rochester) presented several unconventional methods for patterning nanoparticles into ordered arrays. P. Hammond (MIT) introduced two alternative techniques for patterning-polymer stamping and polymer-transfer printing. R. Penner (UC-Irvine) discussed the fabrication of metal nanowires by electrochemical deposition and their use in chemical sensing. R.G. Nuzzo (UIUC) reported progress in the fabrication of complex architectures by dynamic and soft lithographic patterning. J. Jacobsen (MIT) discussed the fabrication of all-inorganic logic elements by

\section{David Turnbull Lecture Addresses Nanoscale Structures}

The 2003 David Turnbull Lectureship was awarded to Ellen D. Williams of the University of Maryland. In her lecture, "Nanoscale Structures: Lability, Length Scales, and Fluctuations," Williams said that crystalline nanostructures are neither molecules nor are they macroscopic solids. A large fraction of the material is on the surface, and edge-boundary fluctuations determine the structural evolution of nanostructures. At the nanoscale, such structures include $10^{5}$ or fewer atoms and give rise to special physics, including quantum confinement.

In order to fundamentally understand the behavior of such nanostructures, it is important to solve several problems, Williams said. These include structural lability or the magnitude of changes and strength of the driving forces, the means to capture properties of interest that are not at the atomic scale or at the continuum level, and fluctuations. Williams covered each of these topics, including models for understanding how the nanostructures behave and scanning tunneling microscopy tests for experimental evidence. She cited several remaining challenges such as the prediction of environmental sensitivity of thermodynamic step parameters from the atomic-scale understanding and the correlation of direct observations of structural fluctuations with fluctuations in materials properties.

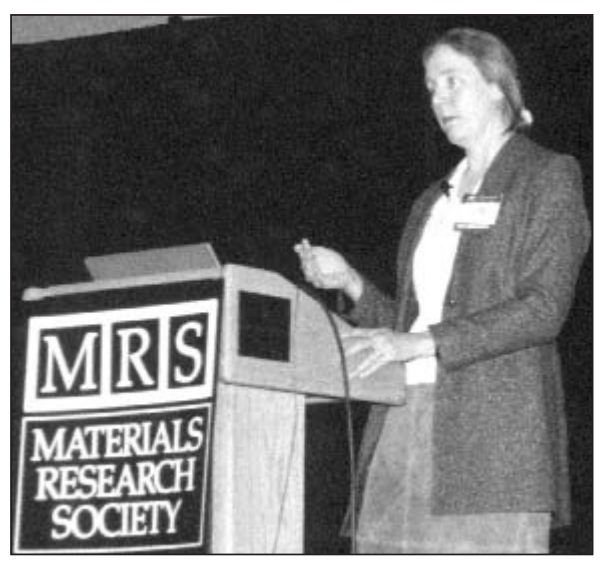

Ellen D. Williams of the University of Maryland presented her David Turnbull Lecture, "Nanoscale Structures: Lability, Length Scales, and Fluctuations." liquid embossing. J. Aizenberg (Bell Labs/Lucent) demonstrated the fabrication of nanostructures by controlled generation of disorder. J.B. Wiley (Univ. of New Orleans) demonstrated the fabrication of structured nanowires by templating. P.F. Nealey (Univ. of Wisconsin) discussed how epitaxial self-assembly of block copolymers was used to generate patterned nanostructures. C.J. Murphy (Univ. of South Carolina) elaborated on the synthesis and self-assembly of gold nanorods. O.D. Velev (NCSU) demonstrated how on-chip dielectrophoretics could be used to manipulate and assemble liquid droplets. A. Stein (Univ. of Minnesota) described the fabrication of multifunctional photonic crystals by colloidal templating. I. Aksay (Princeton) discussed the use of an electrical field in directing the assembly of spherical colloids. C.K. Ober (Cornell) illustrated how bottom-up and top-town approaches could be combined to fabricate 3D periodic structures. J.W. Perry (Georgia Tech) discussed the use of two-photon lithography in fabricating 3D structures. T.J. Bunning (WPAFB) discussed the fabrication of $3 \mathrm{D}$ periodic structures in polymer-dispersed liquid crystals. P.V. Braun (UIUC) discussed the use of multiphoton polymerization in generating waveguiding structures in photonic crystals. J.A. Lewis (UIUC) described a simple and versatile approach to 3D periodic structures.

Symposium Support: ITRI of Taiwan and NanoInk.

\section{Quantum Dots Make Leaps into Electronic, Photonic, and Biological Realms}

(See MRS Proceedings Volume 789)

Symposium $\mathrm{N}$ enabled the connection of several research communities interested in the making and application of nanostructures whose properties result in a large measure from quantum mechanical effects. Among the highlights of the symposium, P.M. Fauchet (Univ. of Rochester) led an evening session on silicon nanocrystals in which speakers debated the scientific possibility of silicon nanocrystal lasing. Throughout the symposium, the role of one to a few charges in semiconductor nanostructures was emphasized as a novel way to tune electronic and optical properties. This started with a theory presentation by A.L. Zunger (NREL) and continued with the presentation of data by F. Henneberger (Humboldt-Universität Berlin) on the spectra of singly and multiply charged single surface-grown quantum dots (QDs), an 
experimental tour de force. L. Samuelson (Lund Univ.) also showed the excellent negative differential conductance that can be achieved with nanothreads grown by MBE. In recent years, the field of nanostructures has grown so much that whole groups can now fully specialize in the making of nanomaterials. In particular, T. Hyeon (Seoul Natl. Univ., South Korea) and Y. Xia (Univ. of Washington) presented many novel and highly controlled nanostructures grown by colloidal methods. The symposium connected to biology with various schemes for using inorganic semiconductor and magnetic nanoparticles as markers. M.G. Bawendi (MIT) addressed the use of near-IR emitting QDs for deep-tissue imaging in live animals as a means to identify the correct lymph node for biopsy, which could provide significant benefits to cancer surgeons and their patients. S.M. Simon (Rockefeller Univ.) used QDs for longterm imaging of live cells and investigated the toxicity effects on cell growth and functions. QD-labeled tumor cells injected intravenously into mice were followed as

\section{Frontiers of Materials Research: From Radical to Reality}

Symposium X on Frontiers of Materials Research presented a program of radical ideas such as interfacing silicon technology with the human body (Leigh Canham of pSiMedica Ltd., U.K.), the production of low-cost devices and circuits on arbitrary surfaces (Thomas N. Jackson of The Pennsylvania State University), and communicating science through the eyes of a professional photographer (Felice Frankel of the Massachusetts Institute of Technology). The program provided some insight into materials processing (Harold G. Craighead of Cornell University; David L. Kaplan of Tufts University) and materials properties (H. Eugene Stanley of Boston University). Materials research with marketing potential was described by Christopher Hebling (Fraunhofer Institute for Solar Energy Systems), who discussed micro fuel cells as a supplement to or substitute for batteries, and by M. George Craford (LUMILEDS Lighting LLC), who covered solid-state lighting through light-emitting diodes (LEDs).

Craford began his talk with an image taken from a satellite that shows the Earth lit up at night by artificial light sources. "If we can do what many think we can do, we can replace most of these lights with solid-state lighting in the future," he said. In the evolution of lighting, LEDs were barely a factor until the 1980s. After significant growth and improvement in materials in the 1990s, LEDs can now be made with a luminous efficiency of about $30 \mathrm{~lm} / \mathrm{W}$, twice the efficiency of an incandescent bulb. From an external efficiency of 5\% 15 years ago, $50 \%$ or more of the light generated inside an LED makes it to the outside world today. This increase is due to the development of high extraction efficiency structures, such as thin films with reflective intermetallic and scattering features. Increased power has also produced better output intensities. In 2002, 5 W LEDs were capable of giving off 120 lumens.

One of the main challenges for the replacement of incandescent and fluorescent bulbs is the production of white light by LEDs. This can be done in two ways: by phosphor downconversion or by color mixing (blending RGB LEDs to produce white light). The phosphor conversion process is currently the simpler, dominant method. The company's Luxeon product uses a conformal coating of phosphor granules on LED die to improve the uniformity of light emitted as a function of viewing angle. Craford said that a recent product release combines YAG:Ce with CaS:Eu compositions to more closely match the spectrum of blackbody radiation. With a color-rendering index (CRI) of 90, this product is an improvement over the CRI of 75 obtained for YAG:Ce alone.

In another area with marketing potential, micro fuel cells, particularly for portable applications, can significantly improve the current energy requirements of electronic devices, said Hebling. They also carry significant potential for applications in industrial settings and for the military. Among the desirable features of portable fuel cells are the high energy and power density, the separation of energy (fuel cartridge) and power (fuel cell), minimal degradation, and instant recharging.
Possible fuels for fuel cells include pure hydrogen, methanol, or hydrogen produced on-site by means of chemical hydrides and micro-reformed hydrocarbons. Among the materials challenges still to be addressed are improved membranes, electrodes with reduced catalyst loading, and low-cost bipolar plates. Hebling said that the first prototypes of fuel cell systems are ready for the commercial market. The uncertainties that researchers are still confronting is the competitiveness of fuel cells with batteries in terms of cost, reliability, safety, and efficiency.

Hydrogen shows up again in a discussion of the materials properties of water. While most researchers have attributed the unique properties of water to its tendency to bond hydrogen, Stanley said that the local geometry of water is a more important factor. Each water molecule is tightly bound to four neighbors in a tetrahedral structure. How these adjacent tetrahedra align determines the properties of liquid water, he said. A dense-packed structure with tetrahedra nestled one inside the other produces a local minimum ("Well 1") in the energy versus distance curve. However, if the tetrahedra align in a less-dense "base-to-base" configuration, an alternative, lower local minimum ("Well 2") occurs in the energy versus distance curve at a greater separation distance. Because it depends on geometry, all liquids with tetrahedral geometries have the potential to form two liquid phases. Stanley calls the water in energy Well 1 "high-density liquid" (HDL) water, and that in Well 2 "low-density liquid" (LDL) water. The existence of two liquid phases explains why the entropy of water increases with decreasing temperature and why the thermal expansion of water is smaller than expected, even at high temperatures. Stanley presented a revised phase diagram showing these two phases of liquid water, proving once again how even the most well-known materials can sometimes bring on surprises.

By using high-resolution patterning of films such as parylene polymer metals and dielectrics, Craighead is developing new capabilities in biomaterials processing and utilization. The patterned polymer could be used to pattern sensitive biomolecular films such as lipid bilayers with dimensions at the micrometer scale. Using zero-mode waveguides in a thin aluminum film, light confined to a 5-nm-wide window can be used to interrogate the region around a single molecule, such as a bioactive receptor. Chemicals can then be introduced into the open end of the polymer well, and reactions between the bioactive molecule and these chemicals can be monitored using fluorescence methods.

This technique has allowed Craighead and his colleagues to follow the activity of a single DNA polymerase molecule in real time with single-base resolution. Fluorescently labeled nucleotide analogues were added to the well containing the DNA polymerase molecule, and the enzymatic synthesis of the complementary DNA strand was followed by tracking the fluorescent nucleotide analogues. Bursts of fluorescence could be observed when all reagents necessary for DNA synthesis Continued on page 193. 
they extravasated into lung tissue. QDlabeled tumor cells were quantitatively and qualitatively indistinguishable from unlabeled tumor cells. Carbon nanotubes, somewhat of an "orphan" of the meeting without a dedicated symposium, were nevertheless present in Symposium N. The opening presentation on fluorescence and Raman spectra of single nanotubes, contributed by T.D. Krauss (Univ. of Rochester), was particularly insightful. Symposium Support: Evident Technologies and ONR.

\section{Nanotubes Separate and Conquer}

Continuing to be an exciting area of research, work on fullerenes and SWNTs was discussed for much of Symposium O on nanostructured organic materials, including several emerging materials and biological applications, the spinning of strong nanotube fibers, the formation of aligned nanotube membranes for molecular transport, the use of nanotube fieldeffect transistors and chemical and biological sensors, and the use of endohedral fullerenes as MRI contrast agents.
Frontiers of Materials Research continued from page 192

were present. The researchers also looked at single-molecule analysis in one-dimensional constricted environments-small tubes with a single degree of freedom in the $z$ direction. Nanocapillary tubes as small as $250 \mathrm{~nm}$ in diameter were used for a high-speed fluidic screening of DNA fragments. DNA fragment sizes, which are proportional to the number of photons emitted in a given fluorescent burst, were measured. The abundance of the bursts indicated the relative concentrations of the DNA fragments of various sizes. The intervals between bursts corresponded to the total DNA concentration. Craighead said that a major advantage of this type of reaction screening is that it requires 1 million times less material than similar analyses using agarose gel methods.

In another area of materials processing, Kaplan gleaned design rules from nature while exploring bioprocessing of silk proteins. Silk, as constructed by nature, resists compression, has an unusual combination of strength and toughness, and is insoluble in water, even though it is synthesized in an aqueous environment. In describing the bioprocessing of silk using protein and genetic synthesis, Kaplan discussed electrospinning of fibers from genetically engineered materials as well as silk film processing. For the silk processing models, the method is relatively simple but it can lead to remarkable functions; using water content to control the assembly of complex hydrophobic polymers can lead to novel processing routes, green chemistry processing options, and new materials. In addition, "artificial" control can be used to regulate the process. The process can be emulated in vitro to generate new materials and new insights. Better fiber materials, Kaplan said, may be obtained upon answering the fundamental questions of how silk is processed in water to achieve remarkable properties and what can be learned from this process that could lead to new ways to think about polymer processing in general.

"The materials world is stunningly beautiful," said Frankel by way of introduction of her topic on scientific imaging; "so why not get other people to see it?" Working with scientists, Frankel has taken images of many different phenomena-the filaments formed by Scotch tape as it is pulled from a surface to demonstrate adhesion, a sinusoidal curve of water droplets on a surface to show hydrophobic properties, and plastic templates self-assembling in a liquid. While these images are visually striking, Frankel said, "This is not about art. This is about information in science." She urged scientists to think more about the presentation of their work so that they can get the information across, along with the excitement it engenders. Why not tell a story when showing a picture of a chip that delivers drugs? she asked. She accomplished this by showing the back of the chip, where the holes for drug delivery are located, instead of just the front of the chip. Similarly, by placing a microchip on top of a dime used as a scale marker instead of adjacent to it, she directed the viewers' focus to the subject of the photograph-the chip, instead of the dime. Frankel usually colors her SEM images to emphasize a feature to tell a story and she encouraged scientists to do the same, but advised her audience to always indicate in a caption that the coloring was added digitally.

Implantable biomaterials have undergone an evolution from inert biomaterials, to degradable biomaterials, to future smart and active biomaterials, said Canham. He said that microelectronic implants have come a long way, starting with radio pills and pacemakers in the 1950s to state-of-the-art therapeutic MEMS currently under development. Four types of therapeutic MEMS devices are likely to emerge in the near future, he said: electrical stimulation, therapeutic sensors, therapeutic actuators, and therapeutic scaffolds. Canham outlined the steps for getting such devices through the regulatory process and discussed issues of concern, including interfacing with the body, 3D microfabrication, in vivo sensing, in vivo powering, and data transmission. With increasing synergies between silicon and advanced medical technologies, Canham stressed that semiconducting silicon can be made much more biocompatible than previously thought. He predicted widespread, minimally invasive in vivo applications of therapeutic MEMS.

In his talk regarding circuit miniaturization, Jackson said, "NonMoore's law electronic progress to come will be as stunning as Moore's law progress has been." In his "Tale of Two Substrates," Jackson introduced a high-temperature $\alpha-\mathrm{Si}: \mathrm{H}$ compound on Kapton (a polymer) that he termed an "evolutionary" technology. This technology could prove useful in such applications as photovoltaics for space use, gamma-ray detectors, and strain-bridge arrays. The second "tale" featured a low-temperature polyester for organic thin-film transistors (OTFTs). This is a revolutionary technology, he said, because the very low-temperature process would allow the material to be deposited on cloth and paper. The OTFT technology uses pentacene as the functional organic semiconductor. Using a low-temperature vacuum deposition process, Jackson has produced thin films of pentacene with large dendritic grains that self-organize in terraces on the substrate surface. Organic semiconductors often behave more like insulators than conductors, making electrical contact to the device a problem. However, Jackson's group has produced simple circuits such as five-ring oscillators and 48-transistor divide-by-two circuits that operate at $1 \mathrm{kHz}$.

Eventually, when organic semiconductor detectors can be deposited on any surface, Jackson envisions a smart medical bandage equipped with fluid, temperature, and gas sensors that could help physicians detect problems earlier and improve their diagnostic abilities over their current accomplishments. In a radical prediction, Jackson said that 20 years from now - considering that $10^{18}$ transistors are already being produced per year-there will be more transistors than there will be cells in the total number of human bodies on earth, which is food for thought for those who think computers may one day take over the world! 
Another area of intense interest was the preparation of nanostructured materials using supramolecular chemistry. Researchers reported on small molecules that are designed to self-assemble into conductive wires only a few nanometers in diameter. Materials that self-assemble into simplistic computational devices point the direction toward nontraditional molecular computers. Other speakers described nanostructured tubular materials, also prepared through self-assembly, with applications in drug delivery, as antimicrobials, and in catalysis. The separation of semiconducting from metallic SWNTs was reported by several groups through the formation of supramolecular complexes with single-stranded DNA and with amine-terminated surfactants. These separation techniques represent a crucial step in the development of SWNTs as molecular entities. Covalent side-wall functionalization of SWNTs with aryldiazonium salts was also described. This solvent-free process increases solubility, improves dispersion of the SWNTs in polymers, and shows some selectivity between metal and semiconducting SWNTs.

\section{Structure and Dynamics of Confined Molecular Systems Explored (See MRS Proceedings Volume 790)}

In Symposium $\mathrm{P}$ on dynamics in small confining systems, various points of view were shared on fundamental questions of how spatial restrictions modify a system to behave significantly different than in the bulk, how this difference relates to the molecular properties, and how it can be probed. There appears to be a continuing interest in the dynamics and thermodynamics of confined molecular systems. Dynamics in biologically oriented systems and in microfluidic devices were introduced. Included were presentations on intercellular transport, transport in membranes, biomolecules confined to nanopores, single molecular experiments and electrokinetic effects, and mixing and separation in microfluidics. Of special interest were sessions on friction and nanorheology, where new experiments and theoretical approaches were discussed. The possibility was raised that sheared liquids between nearby surfaces may, in the sliding state, display processes on many scales. The underlying mechanism for this hierarchical behavior is still not known. New analytical and numerical (molecular dynamics) results have been introduced, proposing frameworks for understanding the structure of liquids at interfaces, static friction, shear thinning, mechanisms of energy dissipation, and phase transitions under confinement. Methods to control friction enable the elimination of chaotic stick-slip motion and modify frictional forces. Clearly, in spite of new experimental and theoretical investigations, a microscopic-level understanding is still missing. The need for new approaches has been recognized and the possibility of introducing optical probes to sense local dynamics was discussed. Other sessions dealt with various ways to probe the nature of liquids near interfaces. Notable among these methods were grazing incidence diffraction experiments, dynamic force spectroscopy, surface force apparatus, NMR, and dielectric relaxation. Glass-forming fluids have proven interesting in the investigations of the role of confinement on ordering and phase transitions. Recent advances in the dynamics of wetting were also covered. Spreading of ultrathin liquid films on patterned solid surfaces and the influence of wetting properties on diffusion and sliding in confined systems were discussed. Direct experimental studies have found a relation between slip effects and wetting at fluid-solid interfaces.

Symposium Support: ACS Petroleum Research Fund and ONR

\section{Nanostructures Enable Unique Mechanical Behavior (See MRS Proceedings Volume 791)}

Among the most important issues discussed in Symposium Q were experimental data, theoretical work, and computer models concerning plastic deformation and fracture mechanisms in nanostructured materials and nanocomposites, which, in general, are different from those in conventional coarse-grained polycrystalline and composite materials. The nanoscale and interface effects cause the effective action of competing conventional and unusual deformation modes that are responsible for the unique mechanical properties of nanomaterials. Ductility, high strain rate, and low-temperature superplasticity of nanocrystalline materials represent the subject of growing fundamental research efforts motivated by a range of new applications of these materials in net-shaping technologies. The fabrication of nanotube-polymer composites, nanotube-diamond composites, and nanocrystal-glass composites offers a promising strategy for the synthesis of superhard materials with enhanced mechanical characteristics for various structural and functional applications. Thematic sessions covered nanoscience and nanoengineering of bulk and composite materials, thick coatings, and thin films with enhanced mechanical properties for structural and functional applications. Progress in a wide range of applications for these new materials crucially depends on the development of new fabrication and processing technologies, along with a fundamental understanding of the relationship between the structure and properties. Symposium Support: NSF and ONR.

\section{From Nuclear Reactors to Semiconductors, Energetic Beams Play a Role}

(See MRS Proceedings Volume 792)

Radiation with energetic beams or ion implantation can dramatically enhance or degrade the properties of materials. The topic is of interest to materials researchers working in the fields of nuclear engineering, environmental engineering, nanoscience and engineering, and semiconductor industry. Symposium R covered a very broad scope of topics on radiation effects and ion-beam modification of all kinds of metal, ceramic, and polymer materials. These topics included radiation damage in materials for nuclear fission and fusion reactors, radiation effects in materials for nuclear waste management, ion-beam processing of nanostructures and semiconductor devices, ion-beam modification of the physical properties of materials, computer simulation and modeling of the interaction between energetic particles and solid targets, advanced characterization and processing techniques (e.g., with focused ion beams), and ion-beam-assisted deposition and surface modification.

Symposium Support: JEOL USA, ORNL, and Univ. of Michigan.

\section{Pace of Thermoelectric Materials Innovation Accelerates (See MRS Proceedings Volume 793)}

The area of thermoelectric materials research has seen an acceleration in the pace of innovation as well as materials and device improvements. J.P. Heremans (Delphi Research Labs) opened Symposium $S$ with recent work on the electrical transport and optical properties of Bi nanowire composites. R. Funahashi (AIST) introduced a new high thermoelectric figure of merit for oxides. These materials are of interest for high-temperature solidstate power conversion due to their high melting points and resistance to oxidation at elevated temperatures. His work includes high-throughput screening of compositions, rapid characterization techniques, and the design and testing of thermoelements and devices based on these materials. G.D. Mahan (PSU) presented a theoretical interpretation into recent high-pressure measurements on thermoelectric materials. These results 
indicate an enhancement in the thermoelectric properties of certain materials under high pressures. This approach not only introduces new avenues for further investigation but also new physics for the transport properties of semiconductors under high pressure. M.S. Dresselhaus (MIT) gave an overview of research on low-dimensional and nanostructured materials for thermoelectric applications. This work indicates that lower dimensional materials (i.e., nanowires and even quantum dot semiconductors) will result in enhanced thermoelectric properties due to a greater opportunity for control of individual parameters. This is clearly one way that this field is enhancing a basic understanding of the physics of low-dimensional materials and phenomena.

Symposium Support: GM RED, Keithley Instruments, Marlow Industries, Melcor, Quantum Design, and Thermal Technology.

\section{Insight into Self-Organized \\ Processes in Semiconductor \\ Heteroepitaxy Revealed}

(See MRS Proceedings Volume 794)

Symposium $\mathrm{T}$ addressed several issues related to the understanding, control, and applications of several self-organized processes in semiconductor epitaxy, including strain-induced self-assembly;

\section{Poster Prizes Awarded at the $\mathbf{2 0 0 3}$ MRS Fall Meeting}

The 2003 MRS Fall Meeting chairs awarded prizes for the best poster presentation. Prize recipients received $\$ 500$, a certificate, and the honor of having their posters displayed for the remainder of the Meeting. Posters and authors awarded prizes were (A5.75) Evolution of Mesas on Si(111) Surface Under Sublimation, K.-C. Chang and J. Blakely (Cornell University); (E6.6) Surface Phase Transitions of Layered Perovskite $\mathbf{C a}_{(2-x)} \mathbf{S r}_{x} \mathbf{R u O}_{4}$, R. Moore (University of Tennessee), S.V. Kalinin,

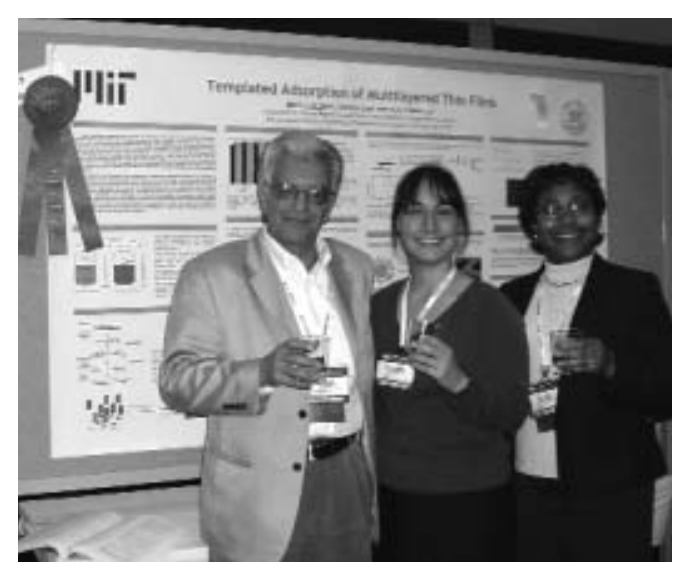
A.P. Baddorf, and R. Jin (Oak Ridge National Laboratory), J. Zhang (Florida International University), and I. Ismail, D.G. Mandrus, and E.W. Plummer (Univ. of Tennessee, ORNL); (H3.41) Molecular Imprinting of Biomineralized CdS Nanostructures: Crystallographic Control using Self-Assembled DNA-Membrane Templates, H. Liang, T.E. Angelini, P.V. Braun, and G.C.L. Wong (University of Illinois at UrbanaChampaign); (J3.19) Surface Potential Measurements of Operating Organic FieldEffect Transistor Devices, K. Puntambekar, P. Pesavento, and C.D. Frisbie (University of Minnesota); (K10.25) High-Performance Organic Light-Emitting Transistors, H. Endoh (NEC, Optoelectronic Industry and Technology Development Association), Y. Sakai (NEC), K. Nakamura (OITDA), M. Nakamura (Chiba University), A. Oda (Research Institute for Organic Electronics, OITDA), and M. Sakai and K. Kudo (Chiba Univ., OITDA); (L11.37) Self-Assembly of Tethered Silsesquioxane "Nanocubes" into Nanostructured Materials: A Molecular Simulation Study, C.X. Zhang, E.R. Chan, M.H. Lamm, and S.C. Glotzer (University of Michigan); (M5.1) Templated Adsorption of Multilayered Thin Films, M. Terrot, C. Ortiz, and P.T. Hammond (Massachusetts Institute of Technology); (M8.16) Spatial Control of Surface Tension Using Inkjet-Patterned Weak Polyelectrolyte Multilayers, J. Choi and M.F. Rubner (Massachusetts Institute of Technology); (U8.1) Subcritical Delamination of Dielectric and Metal Films from Low- $k$ Organosilicate Glass (OSG) Thin Films, Y. Lin and J. Vlassak (Harvard University); (W5.12) Colloidal Photonic Crystals with Graded-Index Distribution, J.-H. Park and D.-Y. Kim (Kwangju Institute of Science and Technology, South Korea); (EE5.25) The Reaction Sequence and Growth Kinetics of $\mathrm{MgB}_{2}$ Layer During ex situ Annealing of Amorphous Boron Film, H.-M. Kim, S.-S. Yim, K.-B. Kim, D.-H. Kang, S.-H. Moon, and Y.-W. Kim (Seoul National University), and H.-N. Lee (LG Electronics Institute of Technology); and (LL7.4) Local Order in Single-Grain Cd-Yb Icosahedral Phase, Y.Q. Wu, M.J. Kramer, and T.A. Lograsso (Iowa State University).

clustering, alloy phase separation, and composition modulation; and long- and short-range ordering.

A number of presentations revealed insight into growth mechanisms and surface-controlled processes. A report on InAs quantum dots (G. Costantini and C. Manzano, MPI-Festkörperforschung, along with F. Montalenti, Univ. of Milano) showed the coexistence of pyramids and domes, similar to that observed in the SiGe system. This result suggests that pyramid-to-dome transitions may be a general phenomenon for Stranski-Krastanov growth. In addition, the first vapor-liquidsolid growth of semiconductor nanotrees and their applications was presented (L. Samuelson, Lund Univ.)

On the subject of nanostructure arrays, extremely regular arrays and stacks of QDs were formed using growth on high-index surface templates (G.J. Salamo, Univ. of Arkansas). In addition, directed assembly of silicon nanocrystals on silicon-oninsulator structures was shown to be a useful template for carbon nanotube growth (M.G. Lagally, Univ. of Wisconsin).

Related semiconductor nanostructures are formed by alloy phase separation, often termed composition modulation. In search of the origins of these phenomena, both experimental and theoretical studies were presented. For example, very regularperiod vertical composition modulation (VCM) was reported in metalorganic chemical-vapor-deposited GaInAsSb alloy layers grown on vicinal substrates (C.A. Wang, MIT Lincoln Laboratory). The VCM formation mechanism was associated with GaAs- and InSb-rich alloy decomposition that is coupled with elastic strain associated with steps and surface undulations.

Spontaneous ordering was also highlighted in the symposium. For example, the effects of ordering on alloy fluctuations and consequent physical properties were revealed (Y. Zhang, NREL); in addition, it was shown that ordered-domain twin boundaries in $\mathrm{CuPt}$ ordered alloys offer a simple means to realize negative refraction for both electrons and light.

A number of presentations showed the promising device applications of selforganized phenomena. For example, MBE-grown InGaAs QD-based verticalcavity surface-emitting lasers operating at $1.3 \mu \mathrm{m}$ with an output power as high as $2 \mathrm{~mW}$ and optical amplifiers with a net gain above $0.4 \mathrm{~dB} / \mathrm{mm}$ and a gain recovery time as short as $115 \mathrm{fs}$ were reported (U.W. Pohl and D. Bimberg, TU Berlin). In addition, above-room-temperature ferromagnetic transitions were reported for Mndoped InAs/GaAs QDs (P. Bhattacharya, 
Univ. of Michigan). This is the first report on a clear observation of the magnetic phase transition temperature (above $300 \mathrm{~K}$ ) in an arsenide-based heterostructure.

Symposium Support: NREL, NSF, Omicron NanoTechnology USA, and Veeco Instruments.

\section{UV Sources and Solid-State Lighting Drive GaN Research}

\section{(See MRS Proceedings Volume 798)}

The main topics discussed in Symposium $\mathrm{Y}$ on $\mathrm{GaN}$ and related alloys were UV lasers and LEDs, bulk substrates, heteroepitaxy, nanostructures, indium nitride, electronic devices, advances in processing, and various characterization techniques. The drive for UV sources and solid-state lighting continues to be an active area, with researchers reporting power levels reaching $20 \mathrm{~mW}$ at $280 \mathrm{~nm}$ under high injection conditions. There is still much room for improvement in terms of the efficiency of these devices. UV lasers were also reported with wavelengths in the range of 358-380 $\mathrm{nm}$. Different approaches to achieving bulk GaN and AlN substrates were discussed. For bulk substrates, the main issue is still the limited size. However, in the short term, quasibulk substrates grown by HVPE and lifted off from the original substrates seem to be the best solution.

Heteroepitaxy of $\mathrm{GaN}$ on silicon is gaining a lot of attention, with the possibility of integration. In the nanostructures session, GaN QDs grown by both MOCVD and $\mathrm{MBE}$ were reported. In the area of impurity doping, there were presentations on $\mathrm{Mg}$ incorporation for $p$-type $\mathrm{GaN}, \mathrm{Mn}$ doping for spintronics, and rare-earth doping for luminescent devices. Another interesting development is the convincing evidence that the direct bandgap of $\mathrm{InN}$ is $\sim 0.65 \mathrm{eV}$, based on material with higher crystallinity. However, the issue of a high residual background electron concentration still needs to be addressed. Preliminary results on InN-based solar cells were also presented.

Symposium Support: AFOSR, ARO, DARPA, and ONR

\section{Understanding Brought to Behavior of Hydrogen in Compound Semiconductors}

\section{(See MRS Proceedings Volume 799)}

Symposium Z brought together discussions of the materials properties and the consequences for electronic and optoelectronic device applications of a range of semiconductor materials including III-V alloys, $\mathrm{ZnO}$, and quantum structures. C.G. Van de Walle (Palo Alto Research Center) tied many of these materials together with a unified theoretical treatment of the effects of hydrogen in com-

\section{Graduate Students Receive Gold and Silver Awards}

During an awards ceremony held on December 3 at the 2003 Materials Research Society Fall Meeting, graduate student finalists received Gold and Silver Awards.

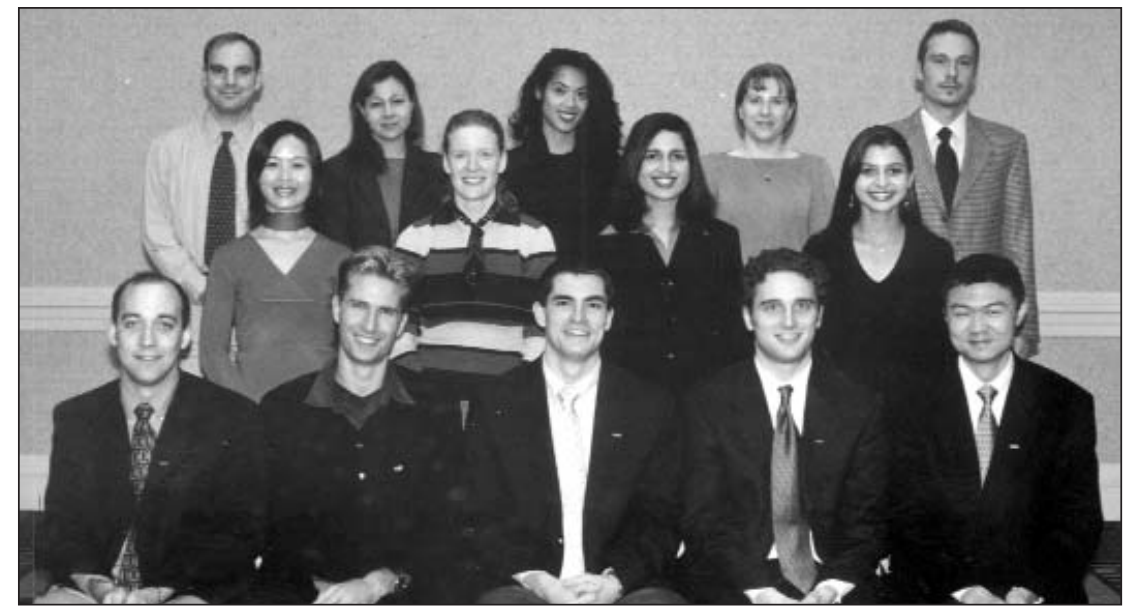

Gold Graduate Student Awards went to (row 1, left to right): Gary R. Maskaly (Massachusetts Institute of Technology), Olaf Gelhausen (University of Technology, Australia), David M. Pustai (University of Delaware), Gregory M. Gratson (University of Illinois, Urbana-Champaign), and Congjun Wang (University of Chicago); (row 2, left to right): Haimei Zheng (University of Maryland), Jessica Winter (University of Texas, Austin), Suniti Moudgil (Massachusetts Institute of Technology), and IIke Arslan (University of California, Davis); and (row 3, left to right): Daniel B. Aubertine (Stanford University), Francesca lacopi (IMEC, Belgium), Sarah M. Estrada (University of California, Santa Barbara), Amanda J. Haes (Northwestern University), and Egon Gross (Technische Universität Munchen, Germany). Not shown is Rongchao Jin (Northwestern University).

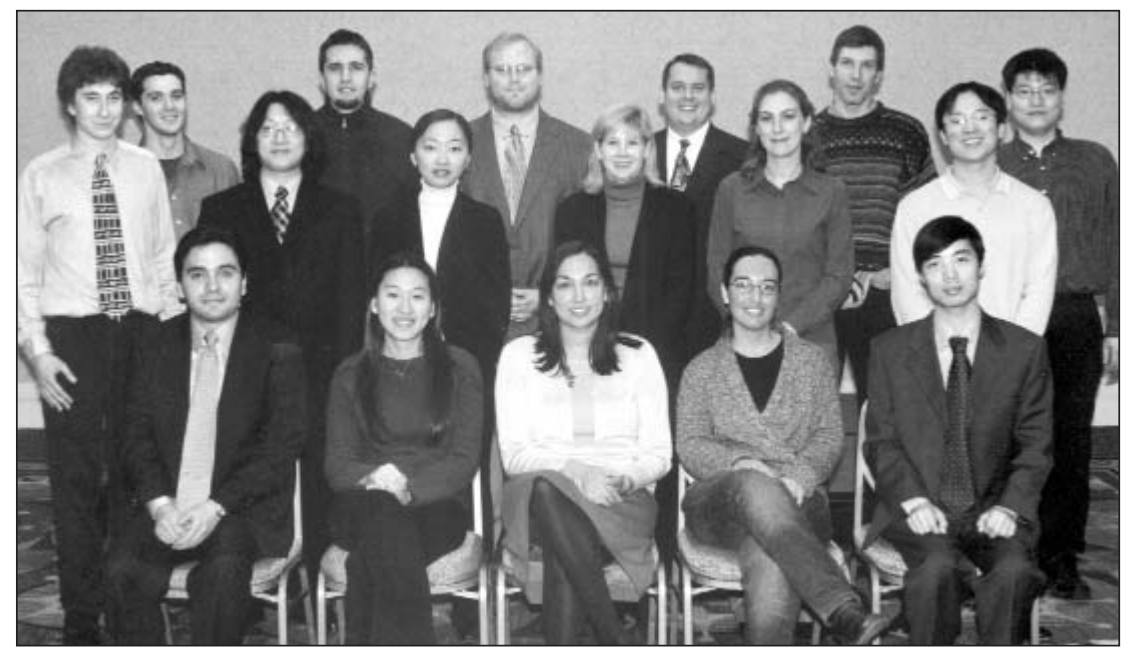

Silver Graduate Student Awards went to (row 1, left to right): Manuel Garcia-Leiner (University of Massachusetts, Amherst), Ting Xu (University of Massachusetts, Amherst), Aditi S. Risbud (University of California, Santa Barbara), Miri Kazes (Hebrew University, Israel), Weidong Li (University of Delaware); (row 2, left to right): Joshua Goldberger (University of California, Berkeley), Junling Wang (University of Maryland), Shirley Ying Meng (Singapore-Massachusetts Institute of Technology Alliance, Singapore), Cynthia A. Mitchell (University of Houston), Maria M.F. Cortalezzi (Rice University), and Ho Won Jang (Pohang University of Science \& Technology, South Korea); and (row 3, left to right): Olivier Guise (University of Pittsburgh), Aleksandar Spasic (Boston College), Thomas E. Vandervelde (University of Virginia), Brandon L. Seal (Arizona State University), Alexander B. Artyukhin (University of California, Davis), and Sungjee Kim (Massachusetts Institute of Technology). Not shown are Tommaso Baldacchini (Boston College), James Zachary Hilt (University of Texas, Austin), and Evgenia Kim (Moscow State University, Russia). 
pound semiconductors, showing that the widely varying behaviors in different semiconductors can be understood in terms of the band lineups relative to the vacuum level. Thus, hydrogen is predicted to be an acceptor in $\mathrm{GaSb}$, but a donor in $\mathrm{InN}$ and $\mathrm{ZnO}$. This work helps to explain why some of these materials are much more difficult to dope $p$-type (or $n$-type) than others, and suggests ways to modify growth or postgrowth conditions to enable the desired doping. The effect of hydrogen and other impurities was discussed in depth in a session devoted to $\mathrm{ZnO}$. Complementary to Van de Walle's theoretical treatment, in a session on growth and defect characterization A.R. Peaker (UMIST) provided a presentation on experimental characterization of energy levels in semiconductors with a discussion of Laplace DLTS spectroscopy, which can resolve the energy levels of defects in nanostructures in a more precise way than the regular DLTS technique. From a device perspective, J.M. Woodall (Yale) discussed progress in InAs for terahertz electronics, concluding that such fast materials may be more cost-effective than nanoscale Si for such applications.

Symposium Support: AFRL, ARO, NREL, ONR, and SNL.

\section{Materials Energized at Nanometric Dimensions \\ (See MRS Proceedings Volume 800)}

The future is "glowing" for energetic/ reactive nanomaterials, according to presentations given in Symposium AA. Energy contents and release rates short of nuclear detonation are involved in the subject area, so predicting and/or testing dynamic events over nanometric dimensions at subnanometer time scales are par for the course. Z. Iqbal and his colleagues at the New Jersey Institute of Technology are investigating the first stages of turning SWNTs into energetic materials for rapid reaction or explosion applications. Their method is to insert hydrogen or $\mathrm{NO}_{2}$ groups onto the inner walls of SWNTs using electrochemical methods.

Iqbal said that the key to efficient performance is to provide nanostructural homogeneity so there is no mismatch in length scales traversed by the energy front.

A nanotube backbone can provide such homogeneity. The high thermal conductivity of carbon nanotubes can supply the rapid heat transfer necessary for an energetic reaction, while the high electrical conductivity allows the reaction to be initiated electrically. The researchers synthesized free-standing sheets, or membranes, of carbon nanotubes that they called "nanopaper," using CO-CVD methods. These membranes were then used as the cathode in electrochemical cells. Depending on the chemical nature of the anode, the electrochemical reaction resulted in the deposition of hydrogen or $\mathrm{NO}_{2}$ groups on the inner walls of the nanotubes. Up to 1.25 $\mathrm{wt} \%$ hydrogen has been deposited in this manner. Preliminary attempts at initiating a rapid reaction using pulsed Nd-YAG lasers at a $532 \mathrm{~nm}$ wavelength have been successful. Further research to increase the loading of hydrogen in combination with $\mathrm{NO}_{2}$ is planned.

Other highlights of this symposium included the synthesis of materials from $a b$ initio equation-of-state descriptions for new energetic molecular structures and intermetallic-forming compounds to an experimental description of sol-gel nanonetwork structures infused with energetic materials; toxicology aspects of airborne nanoparticles relating to inhalation and dermal concerns; characterization (e.g., via AFM of submicroscopic TNT crystals and time-resolved ultrafast Raman, IR, and emission spectroscopy, as compared with atomic-scale modeling of porous silicon hydrogenated material); processing of oxide-free aluminum nanoparticles protected by self-assembled passivating monolayer coatings; properties, both experimental and theoretical, relating to laser-diagnosed pico- to nanosecond energy release rates for aluminum and a molecular dynamics description of chemical energy input to model detonation and shock wave propagation; and applications, including new propellants, underwater detonations, biocompatible nanoporous implants, explosive porous silicon, and burning of nanolayered materials.

Symposium Support: AFRL, LLNL, and Nanotechnologies.

\section{Actinide Stability, Electronic Structure, and Environmental Impact Addressed}

\section{(See MRS Proceedings Volume 802)}

S.S. Hecker, former director of LANL, opened the inaugural symposium on actinides. The technical sessions in Symposium DD included subjects such as actinide phase stability, transformations, and aging; phononic and electronic structure; actinides and the environment; actinide solution and interfacial chemistry; the theory of actinides; and superconductivity, correlated behavior and quantum criticality, including presentations by B. Johansson of Uppsala University and the Royal Institute of Technology of Sweden and G.H. Lander, the director of the Institute for Transuranium Elements in Karlsruhe, Germany.

Symposium Support: LANL and LLNL.

\section{Second-Generation High- \\ Temperature Superconducting Wire Achieves Improved Performance and Manufacturability \\ (See MRS Extended Summaries EXS-3)}

In the first two days of symposium EE, the latest research on high-temperature superconducting coated conductors (CCs) was presented. The past year saw much progress in high-temperature superconductors (HTSs) in terms of improvement in critical currents, lengths of tape, and the speeding-up of fabrication of all the layers, implying a decrease in future manufacturing costs. SuperPower Corp. reported its 18-m long tape with an end-to-end critical current of $111 \mathrm{~A}$ and speeds of $120 \AA$ /s for its MOCVD of YBCO. American Superconductor Corp. reported critical currents as high as $270 \mathrm{~A}$ in a $1 \mathrm{~cm}$ width on short CC samples using the MOD process. ORNL has made significant progress toward all-solution deposition processes for the CC layers using the $\mathrm{La}_{2} \mathrm{Zr}_{2} \mathrm{O}_{7}$ buffer. At the University of Göttingen, Germany, a group reported performance of $481 \mathrm{~A} / \mathrm{cm}$ over $1.4 \mathrm{~m}$ using PLD. Similarly, Theva (Germany) achieved 360 $\mathrm{A} / \mathrm{cm}$ in short pieces by reactive evaporation of YBCO. LANL showed that the IBAD-MgO template texturing can be completed in $3 \mathrm{~s}$, yielding a $100 \mathrm{~m} / \mathrm{h}$ fabrication speed. SNL demonstrated a $10 \mathrm{~s}$ pyrolysis for MOD of YBCO. Fujikura Ltd. reported fabrication of a $100-\mathrm{m}$-long CC using an IBAD template with an end-toend critical current of 38 A. Thicknessdependence of critical currents in YBCO films continues to be studied, and several promising results have been reported with thicker films, including a report from LANL of $1000 \mathrm{~A} / \mathrm{cm}$ width in a short bridge at $65 \mathrm{~K}$. The session on $\mathrm{MgB}_{2}$ featured dramatic progress in thin films and wires of the $40 \mathrm{~K}$ superconductor. The groups from The Pennsylvania State University and Superconductor Technologies Inc. reported two deposition techniques of $\mathrm{MgB}_{2}$ thin films. The technique from the group at Penn State is characterized by the high epitaxial quality and purity of the films while the technique developed by Superconductor Technologies has demonstrated deposition of 4 -in. films as well as films on stainless-steel foil. An international collaboration between the University of Wisconsin, The Pennsylvania State University, Arizona State University, Superconductor Technologies Inc., and the University of Genoa announced the result of record high $H_{\mathrm{c} 2}$ in C-doped $\mathrm{MgB}_{2}$ films over $50 \mathrm{~T}$, a very promising result for high-field applications. LANL reported a $1 \mathrm{~T}$ magnet made from hot-isostatic-pressed powder-in-tube $\mathrm{MgB}_{2}$ 


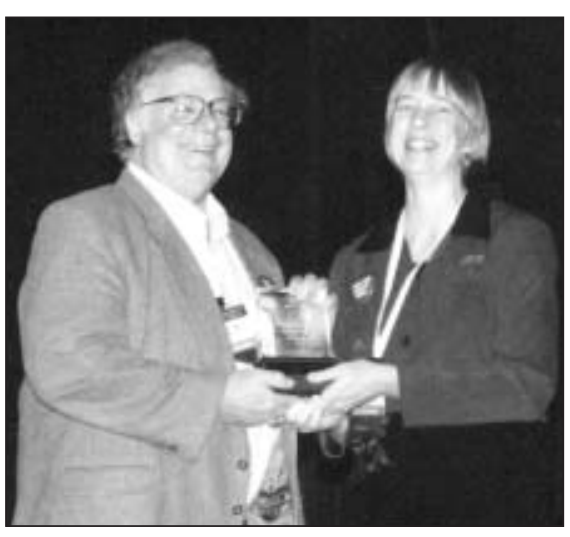

The 2003 Woody Award was presented to Steven Moss of Aerospace Corp. (left) by 2003 MRS President Merrilea J. Mayo (GUIRR, National Research Council). The Woody Award, named after Woody White, one of the early pioneers of the Society, is given annually to an MRS volunteer who has gone above and beyond what is typically expected of a volunteer. The award is usually presented during a private function but was awarded to Moss this year as part of the awards ceremony. Moss chairs the Information Services Committee, whose purview includes proceedings, the Journal of Materials Research, MRS Bulletin, and the MRS Web site.

wire cooled in liquid neon, which demonstrates tremendous potential of $\mathrm{MgB}_{2}$ for applications such as MRI magnets.

Symposium Support: ANL, DOE, and LANL.

\section{Characterization Methods Introduced for Imaging, Analyzing, and Manipulating Materials for Data Storage (See MRS Proceedings Volume 803)}

It is well appreciated that as the size of material objects approaches nanometer dimensions, the materials structural and electronic properties change. This is related to a number of factors, including quantum size effects and the enhancement of the surface/volume ratio with diminishing size. The investigation of these effects and the impact in future recording media will become crucial when recording approaches terabit/in. ${ }^{2}$ densities and the development of instrumentation to explore physical properties at this length scale becomes important. Symposium GG provided a selection of novel approaches in imaging, analyzing, and manipulating materials used for data storage devices, especially at nanometer dimensions. H.J. Hug (Univ. of Basel) presented a novel magnetic force microscope (MFM) that operates under vacuum conditions and demonstrated spatial reso- lution of $<10 \mathrm{~nm}$. MFM has become one of the most widely used imaging techniques for studying magnetic nanostructures. Currently available MFM technology with a typical resolution of $50 \mathrm{~nm}$ has been outpaced by the development of high-density magnetic recording technology (where bit lengths are reaching $30 \mathrm{~nm}$ and below), and improved spatial resolution in MFMs below $10 \mathrm{~nm}$ is clearly needed.

R.M. Wiesendanger (Univ. of Hamburg), who pioneered the development of spinpolarized scanning tunneling, showed examples of atomically resolved imaging of magnetic domain wall structures. H. Brune (Ecole Polytechnique Fédérale de Lausanne) focused on the investigation of the spatial limits of magnetic structures and presented results on the evolution of magnetism from adatoms to 2D nanostructures. R.E. Palmer (Univ. of Birmingham) and Y. Hasegawa (Univ. of Tokyo) used scanning probe technology for improved spatial resolution in chemical imaging. While Palmer used scanning probe energyloss spectroscopy for exciting highly resolved chemical imaging, Hasegawa used an x-ray and synchrotron radiation source combined with scanning tunneling microscopy for elemental analysis.

Symposium Support: FEI, LEO Electron Microscopy, Omicron, and Seagate.

\section{Phase-Change Materials Properties for Optical and Electronic Data Storage Geared for Future (See MRS Proceedings Volume 803)}

Optical data storage systems are key to unlocking the benefits of the Information Technology age. Since the early 1980s, when optical compact disks were introduced into the consumer world, university and industry researchers have developed optical materials capable of storing evergreater amounts of information, now exceeding tens of gigabytes on a digital versatile disk (DVD). For future generations of storage systems, new and improved materials are needed to sustain the need for ever-higher data storage capacities as well as recording and readout rates. M. Wutting (RWTH Aachen), in Symposium $\mathrm{HH}$, introduced an approach to developing design rules for storage materials optimization, a potentially significant breakthrough from the previously prevalent trial-and-error efforts. Optimization is particularly important, as ultrahigh data capacities also require extremely fast media response times. Q. Wang (Natl. Univ. of Singapore/Date Storage Insitution) and J. Siegel (CSIC, Spain), building on the pioneering work of Ohta-formerly from Matsushita and now at ECDshowed that femto- to nanosecond pulses can be used to induce phase changes in storage media, allowing data transfer rates exceeding Gbits/s. K. Kishima (Sony) described optical systems based on solid immersion lenses that can harness the power of these high-performance media. He demonstrated recording densities exceeding 50 Gbits/in. ${ }^{2}$ per layer, allowing storage capacities for a single disk far beyond 100 Gbytes, capable of holding dozens of movies. J. Tominaga (AIST) presented evidence that far-field superresolution storage incorporating phasechange media might also achieve very high densities. Optimized phase-change materials with such extreme performance potentially open the door for the replacement of magneto-optic media, which are expensive and environmentally unfriendly, as discussed by R. Somekh (Plasmon Data Systems). Equally exciting are developments in probe-based solid-state storage systems in which nano-sized spots contain information recorded with micromechanical or optical probes on media that can be either optically or electrically addressed, as reported by researchers from Hewlett-Packard and Samsung, among others. Advances in phase-change materials properties for optical and electronic data storage appear to be capable of supporting sustained growth of the performance of storage products well into the next decade. Additionally, the role of optical data storage systems was expanded by S.R. Ovshinsky (ECD), who proposed a new cognitive computer with both memory and processing functions based on phase-change materials.

Symposium Support: ECD, Hitachi, Matsushita Electric Industrial, Ricoh RED Center, Umicore Materials $A G$, and Unaxis Balzers.

\section{Many Facets of Gems Examined}

The remarkable properties that make gems aesthetically desirable continue to inspire new kinds of materials and new ways of making them. Conversely, the increasing sophistication of materials characterization methods allows gemologists to describe the origin and behaviors of gems with ever-higher precision. A. Cheilletz and P. de Donato (CNRS) reported in Symposium II their use of Fourier transform infrared microspectroscopy to show that oxygen-deuterium stretching vibrations in the range of $2900 \mathrm{~cm}^{-1}$ to $2500 \mathrm{~cm}^{-1}$ can serve as fingerprints for the genesis of emeralds. In the synthesis of diamonds, R. Abbaschian (Univ. of Florida) described progress in the manufacture of large $(>3 \mathrm{ct})$ diamonds using high-pressure/hightemperature split-sphere technology at costs that are becoming competitive with natural diamond production. Even more 
surprising, B. Deljanin (EGL) displayed examples of high-quality, Type IIa gem diamonds formed by CVD. Both techniques easily allow for the synthesis of intensely colored diamonds (including yellow, blue, red, and pink stones), which are exceptionally rare in nature. In a striking example of geomimetics, E. Fritsch (IMN) presented his exhaustive studies of volcanic opals, which demonstrate that the relationship between optical liveliness (opalescence) and the underlying substructure is much more complex than the traditional, idealized model of close-packed silica spheres would suggest. O.D. Velev (NCSU) followed this tour of natural opal permutations with an even more diverse array of normal and inverse opals produced by controlled self-assembly in colloidal solutions for use in photonic devices.

\section{Combinatorial Methods Find Successes in Catalysis and Other Areas (See MRS Proceedings Volume 804)}

Symposium JJ on combinatorial and artificial intelligence methods in materials science saw a diversity of applications for combinatorial and high-throughput research methods and tools, including materials formulations (D.A. Hajduk, Symyx), surface polymerization (J. Genzer, NCSU), scale-up for coatings (K. Ezbiansky, GE Silicones), inorganic films (J. Takeuchi, Univ. of Maryland), and millifluidics (K.L. Beers, NIST). Many examples of the power of these emerging methods to investigate problems in polymers and materials science were presented. Scaleup of combinatorially developed formulations remains an important challenge. One of the effective ways of eliminating the risk of the scale-up "flop," where a material initially developed on a combinatorial scale loses its great performance when reproduced on a pilot and manufacturing scales, was demonstrated in a presentation by Ezbiansky. The impact of combinatorial methods is evident not only in the area of formulations chemistry and physics but also in such diverse areas as electronic materials, hydrogen storage materials, solid-oxide fuel cells, and catalysis. Catalysis remains a strong leader in the application of combinatorial methods. Remarkably, several new success stories of bringing combinatorially discovered catalysts to a production trial were reported. These studies conclusively demonstrate that by the careful development of screening conditions on a combinatorial scale, the performance of combinatorially discovered catalysts is reproduced on a traditional pilot scale. One of the examples given in the symposium by J. Spivack (GE Global
Research) demonstrated a further understanding of catalytic activity, which led to the rapid directed synthesis of new catalyst candidates and the identification of catalysts with substantially higher selectivity.

Symposium Support: GE Global Research, Hysitron, NREL, and NSF.

\section{Modeling and Simulation Incorporate Increased Realism and Complexity}

Striking progress toward direct, atomicscale investigation and prediction of materials preparation, properties, and processing was evident in Symposium KK. Pervasive themes included rapidly growing refinement of chemical realism in multiscale simulations, technical advances to allow treatment of increasingly complex systems (e.g., impurity-induced embrittlement, corrosion passivation in steels, and chemical etching), as well as increased realism for such long-standing challenges as brittle fracture. Extensive use of kinetic Monte Carlo schemes was a clear theme. Substantial improvements were reported in both classical potentials and in electronic-structure methods based on the tight-binding approximation. These were complemented by new methods to include information about forces and energetics at quality levels comparable to the best of modern quantum chemistry. Systems ranging from quantum dots to nano-objects tethered to semiconductor surfaces were discussed.

\section{Quasi-Crystal Research Covers Aspects from Materials Structure and Synthesis to Applications (See MRS Proceedings Volume 805)}

Many aspects of quasi-crystal (QC) physics were introduced in Symposium LL. T. Ishimasa (Hokkaido Univ.) reported on a class of QCs based on a novel type of local order differing from the previously observed "Mackay" and "Bergman" type QCs. He described novel, thermodynamically stable QC phases in $\mathrm{Zn}$ and $\mathrm{Cu}-\mathrm{Ga}$ alloy systems. D.J. Miller (ANL) applied fluctuation electron microscopy for the study of QCs in order to investigate the role of medium-range order on the crystallization behavior of QC-forming alloys. He studied the devitrification of amorphous Zr-Pd alloys prepared by different production routes. In the study of surface science of QCs, R. McGrath (Univ. of Liverpool) demonstrated layer-by-layer growth of icosahedral Al-Pd-Mn by means of STM. On the applications side, A.-P. Tsai (Natl. Institute for Materials Science) reported on the use of QCs as catalysts, demonstrating that $\mathrm{Al}-\mathrm{Cu}-\mathrm{Fe}$ QCs in the form of nanoparticles-partic- ularly at high temperatures-outperform conventional industrial catalysts. Furthermore, the aging properties and the changes of physical properties upon corrosion, an important issue for the application of QCs as coatings or thin films, was addressed by D. Veys (LSG2M-Ecole des Mines).

Symposium Support: Saint-Gobain.

\section{Going Where No Grain Has Gone Before: The Zero-Grain-Size Limit in Metallic Materials}

\section{(See MRS Proceedings Volume 806)}

Amorphous alloys have unique properties that result directly from their disordered structure. High-angle grain boundaries in crystalline alloys have a similarly disordered structure, so one might expect that nanocrystalline metals would share some common features with metallic glasses. The participants in Symposium MM explored these similarities (and some differences), with a particular emphasis on phase transformations and mechanical properties. A.L. Greer (Cambridge) and U. Köster (Universität Dortmund) opened the symposium with a pair of talks describing how an understanding of nucleation kinetics can be used to control the microstructure of nanocrystalline metals produced by devitrification of a metallic glass. Direct evidence to support Frank's hypothesis that icosahedral order in undercooled liquid metals is a barrier to the nucleation of crystalline phases was provided by in situ x-ray diffraction experiments described by K.F. Kelton (Univ. of Washington). J.W. Cahn (NIST) displayed data suggesting that an amorphous phase can be produced by a firstorder nucleation and growth transformation from an Al-Fe-Si alloy melt. The mechanical properties of amorphous and nanocrystalline metals are of great interest. A.C. Lund (MIT) described molecular dynamics simulations that showed that asymmetric yielding can be ascribed to similar atomic-scale shearing events in both amorphous and nanocrystalline metals. M.L. Falk (Univ. of Michigan) presented an extension of the shear transformation zone theory to incorporate thermal effects, which can account for the strain-rate dependence of the viscosity of metallic glasses. Creep experiments described by F. Spaepen (Harvard) allow the kinetics of defect formation and annihilation during homogeneous deformation of amorphous alloys to be explored; for instance, the data show that the defect concentration is reversible and reproducible.

Symposium Support: ARO/DARPA, CNRSLTPCM, and NSF. 


\section{Peidong Yang Named 2004 Outstanding Young Investigator for Nanotechnology}

Peidong Yang, a Chevron Texaco assistant professor in the Department of Chemistry at the University of CaliforniaBerkeley, has been named the 2004 Materials Research Society Outstanding Young Investigator. He is cited for "innovative synthesis of a broad range of nanowire and nanowire heterostructure materials, and the discovery of opticallyinduced lasing in individual nanowire devices." The award recognizes outstanding interdisciplinary materials research by a young scientist or engineer. Yang will present his award talk during the 2004 MRS Spring Meeting in April in San Francisco. The title of his presentation is "Chemistry and Physics of Semiconductor Nanowires."

Yang has made a large number of important contributions to the synthesis and characterization of one-dimensional nanostructures with a large potential for practical applications. Beginning with his doctoral work on columnar defects in superconductors in Charles Lieber's laboratory at Harvard University, Yang introduced the feasibility of nanostructure self-organization. Yang demonstrated that $\mathrm{MgO}$ nanowires could create, by a chemical approach, desired columnar defects in a superconductor matrix that would enhance critical current densities. His approach to synthesizing $\mathrm{MgO}$ nanowires involved nucleation and control of vaporphase supersaturation to direct onedimensional growth rather than the typical two-dimensional deposition. He showed that lattice epitaxy can be used to drive self-organization of nanowires into specific orientations within the bulk, which has broad implications for the design and synthesis of nanostructured materials. He continued his work on novel nanostructured materials as a postdoctoral researcher with Galen Stuckey's group at the University of CaliforniaSanta Barbara.

Within the past four years, with his own research group at UC-Berkeley, Yang's optical studies of $\mathrm{ZnO}$ nanowires has led to the discovery and first demonstration of a nanoscale laser. As reported in his article in Science in 2001 (292, p. 1897), lasing behavior was induced from parallel arrays of $\mathrm{ZnO}$ nanowires. Yang enhanced the efficiency of the excitonic-recombination radiative process by fashioning the emitting crystals as carrier-confining nanowires, which formed natural laser cavities. He has subsequently characterized the stimulated emission and other optical phenomena in these nanowires on a deeper mechanistic basis and has shown how

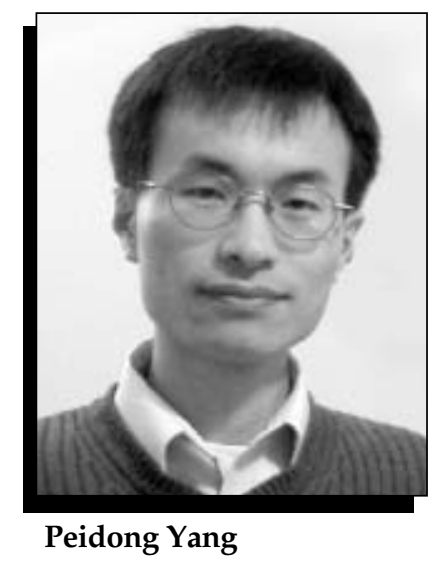

nanowires may be used in photodetectors, chemical sensors, optical switches, and other devices.

In addition, Yang has made significant advances with his demonstration of nanowire assembly using microchannel networks and Langmuir-Blodgett techniques. These results are expected to be of great importance in organizing nanoscale building blocks. His group is credited with being the first to directly monitor very large-scale growth of nanowires; to study nanowire melting and recrystallization; and to fabricate block-by-block, bilayer, and other specific forms of composite nanowires. Most recently, Yang has reported the synthesis of nanowire superlattice materials, specifically, crys- talline silicon germanium superlattice nanowires, which are expected to be excellent nanoscale thermoelectrical materials. Yang has also prepared novel types of nanotubes from noncarbon materials including single-crystal bismuth and gallium nitride.

Yang received his BS degree in chemistry at the University of Science and Technology of China in 1993, and his MA (1994) and PhD (1997) degrees in chemistry at Harvard University. He has more than 80 publications and over 10 patents. He serves as a member of the Executive Committee of UC-Berkeley in the applied science and technology program in the College of Engineering, as a council member of the University of California Discovery Grant within the IndustryUniversity Cooperative Research Program, and as chair of the nanoscience subdivision in the American Chemical Society. He also serves on the scientific advisory board for several journals and book series. Yang's honors and awards include the top 100 innovators 35 years old or younger announced in Technology Review: MIT's Magazine of Innovation, the Beckman Young Investigator Award, the American Chemical Society ExxonMobil Solid State Chemistry Award, the National Science Foundation CAREER Award, an Alfred P. Sloan Fellowship, and the Camille and Henry Dreyfus New Faculty Award.

\section{Plenary Speaker Luiz Davidovich to Discuss Quantum Information}

Luiz Davidovich of the Universidade Federal do Rio de Janeiro, Brazil, will present the plenary talk at the 2004 Materials Research Society Spring Meeting in San Francisco on April 14 at 6:00 p.m. in the San Francisco Marriott Hotel, Salon 7. The title of his talk is "Quantum Information."

Davidovich's research interests are in quantum optics and quantum information, including laser theory, the analysis of the role of decoherence in the quantum classical limit, and proposals for the measurement of quantum states and the realization of quantum logic operations. He has a BS degree in physics (1968) from the Pontifical Catholic University in Rio de Janeiro and a PhD degree in physics (1975) from the University of Rochester. He has been a visiting scientist in many institutions in the United States and Europe and is the author of about 100 scientific papers. Davidovich is a member of the Brazilian

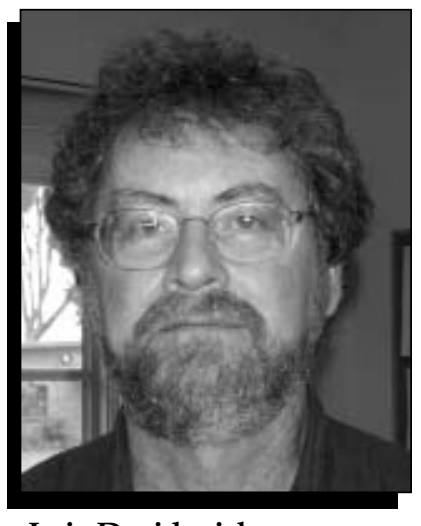

Luiz Davidovich

Academy of Sciences and the Third World Academy of Sciences (TWAS). His honors include the 2001 Physics Award from TWAS and the Grand Cross of Scientific Merit from the Brazilian government. MIR]S 